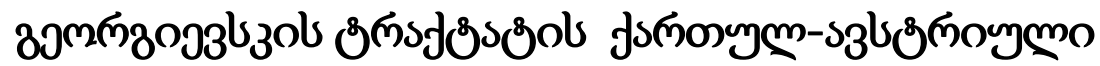

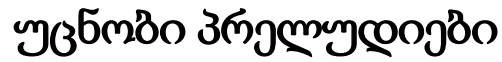

\author{
6s 33 s msdy asayzs

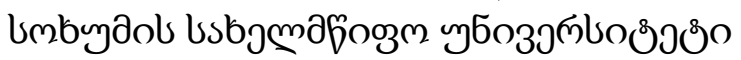

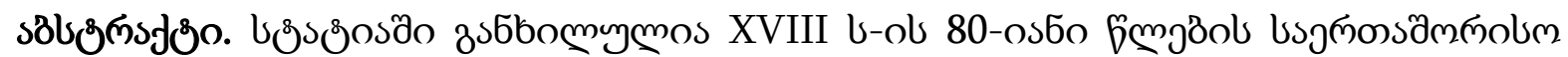

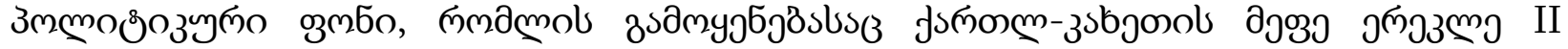

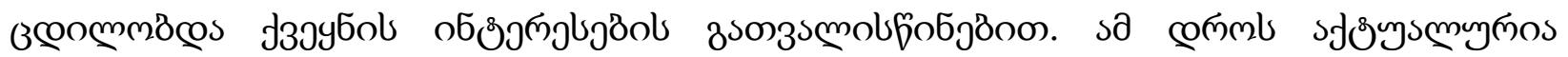

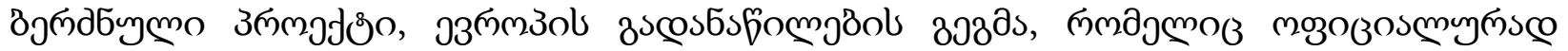

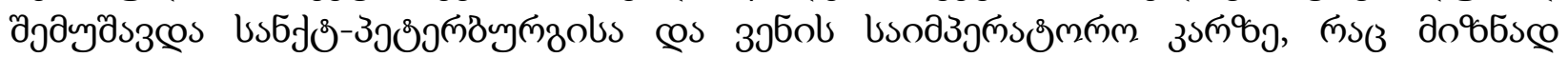

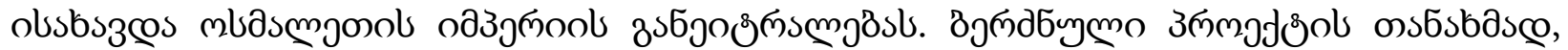

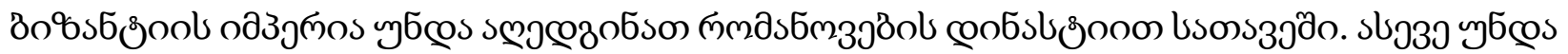

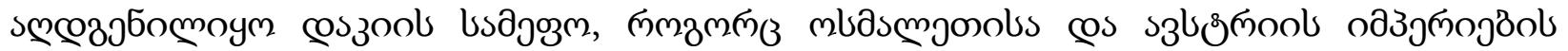

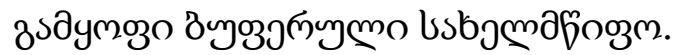

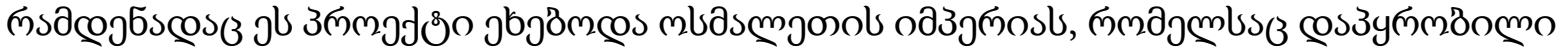

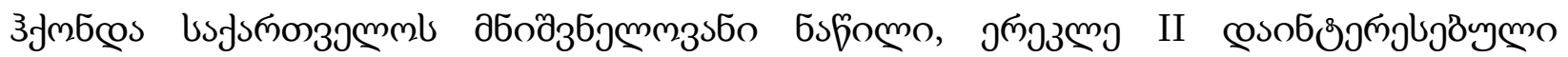

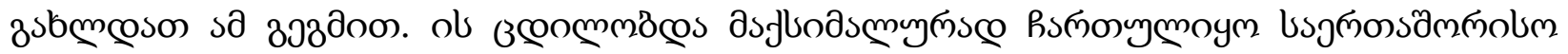

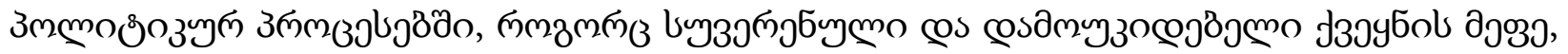

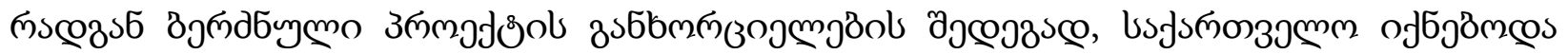

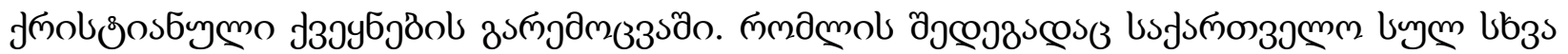

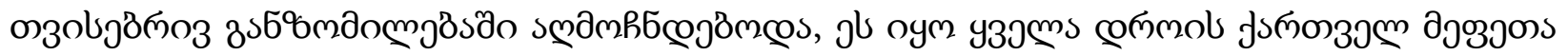
m(3бj8s.

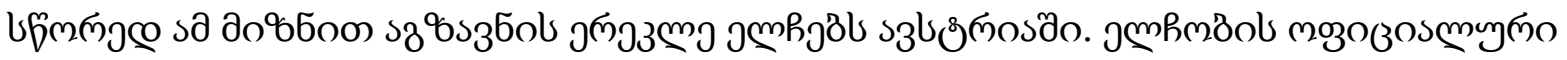

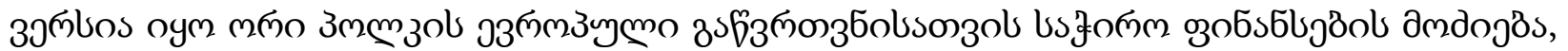

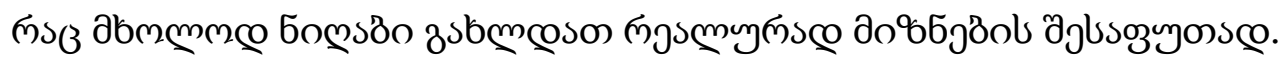

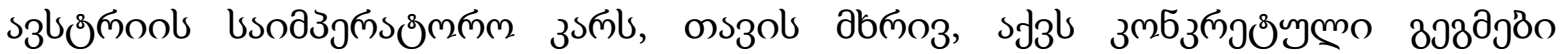

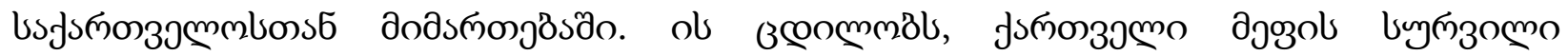

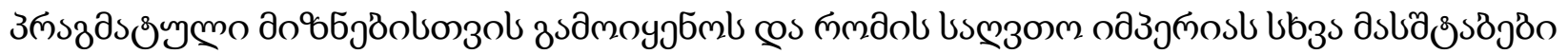

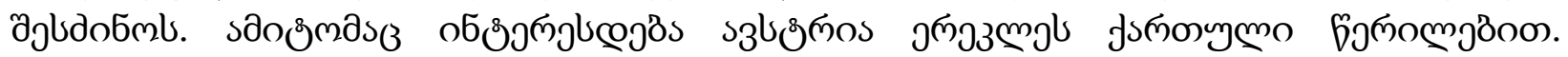
эдбодаб

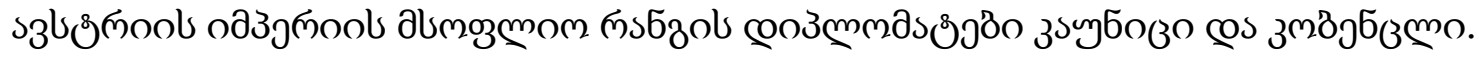

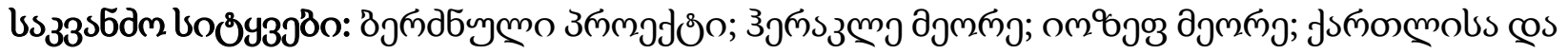

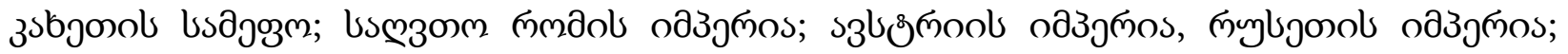

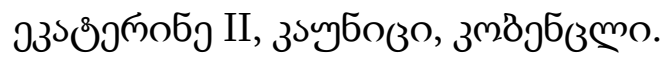




\section{gjlssusmo}

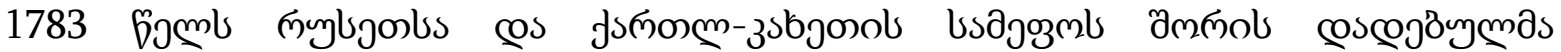

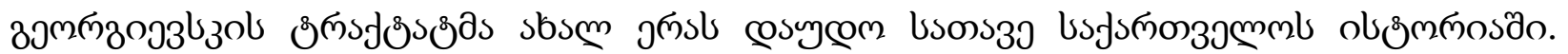

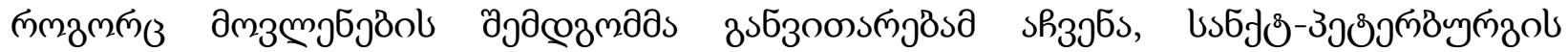

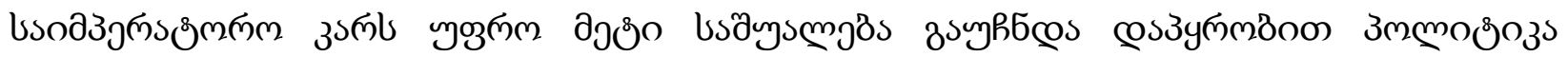

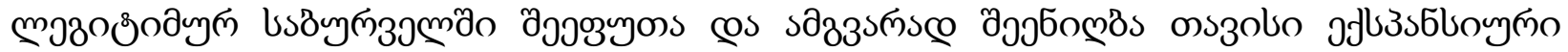

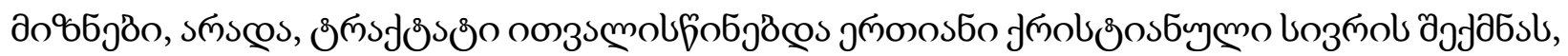

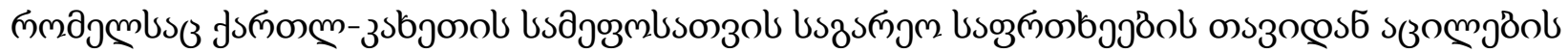

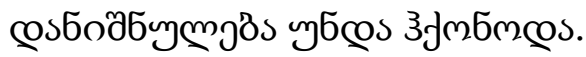

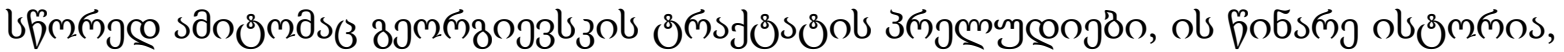

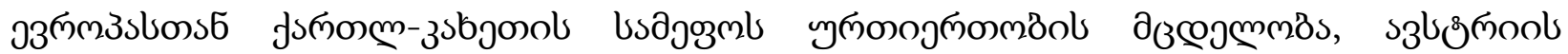

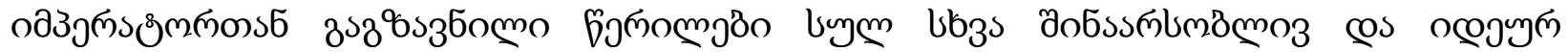

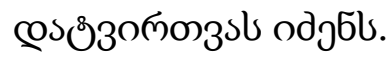

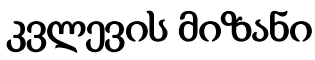

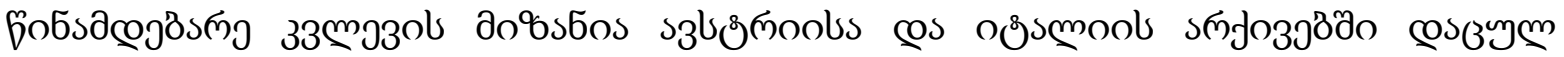

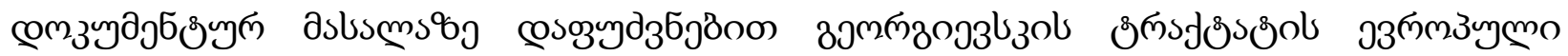

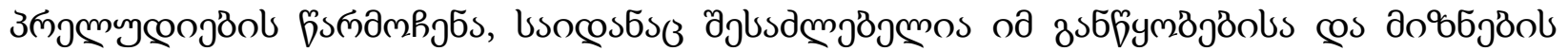

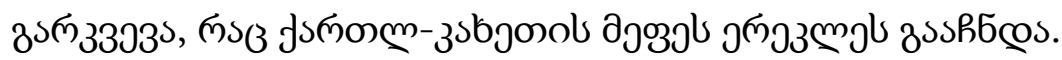

\section{3зलmozol bostbmo}

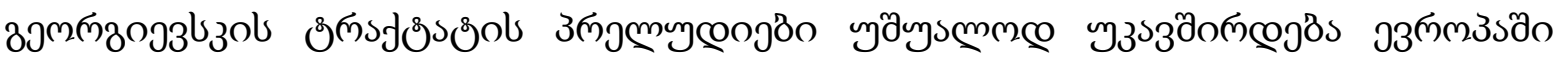

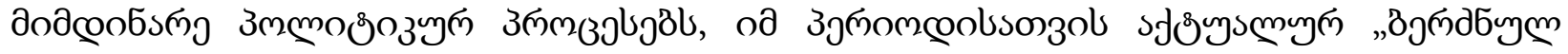

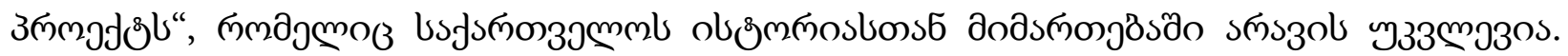

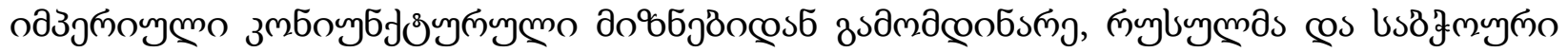

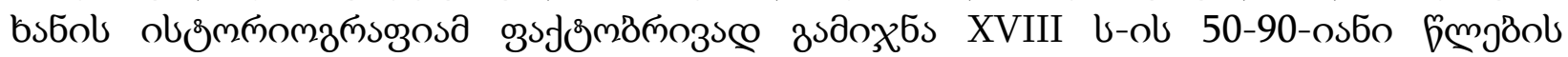

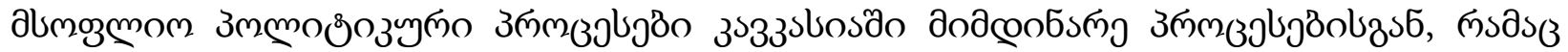

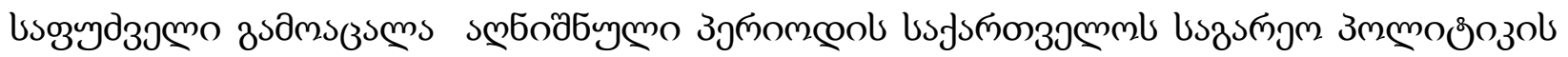

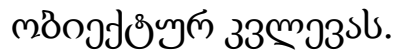

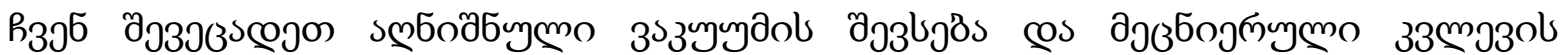

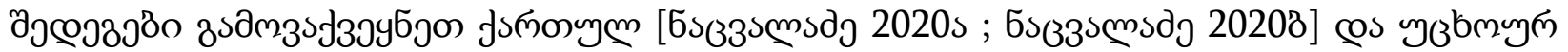
[Natsvaladze 2020a; Natsvaladze 2020b; Natsvaladze 2020c; Natsvaladze 2020d; Natsvaladze

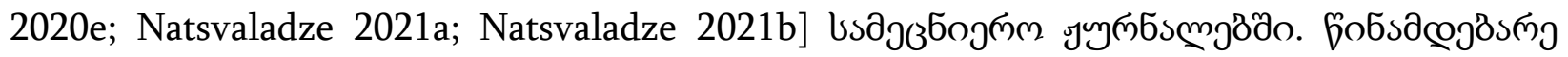

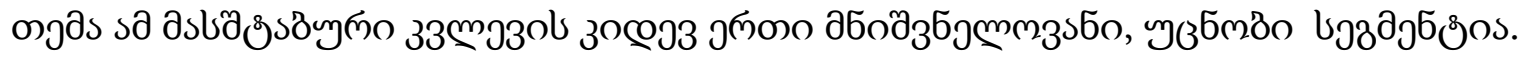

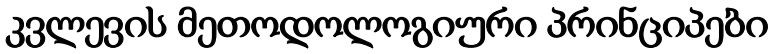

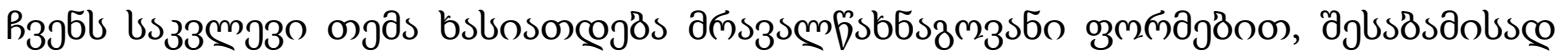

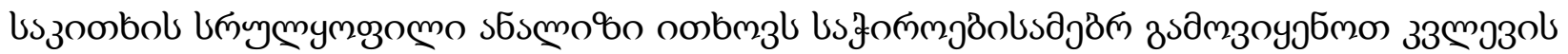

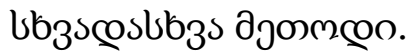

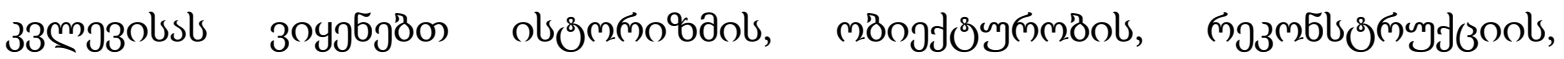

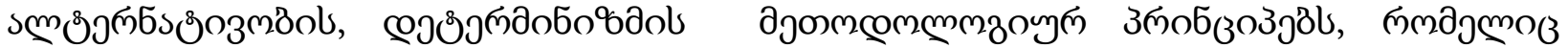

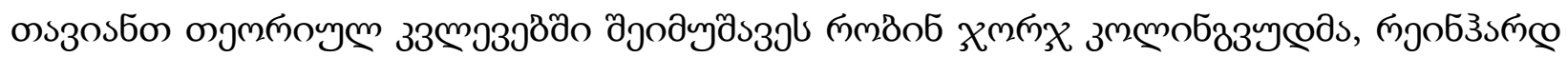

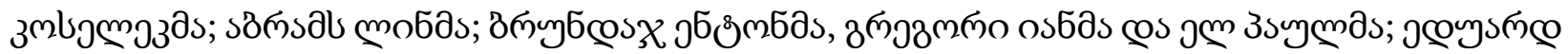




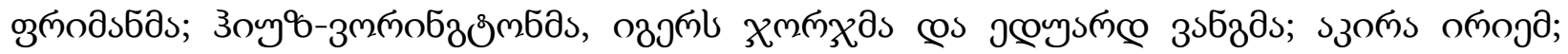

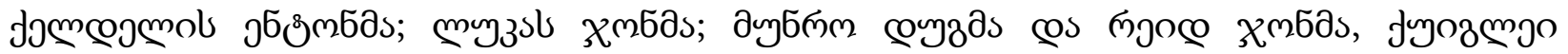

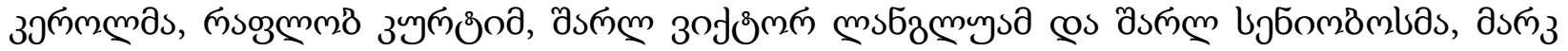

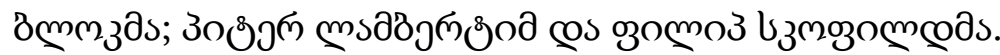

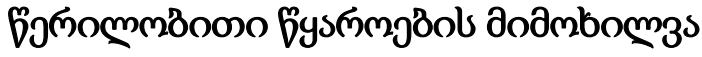

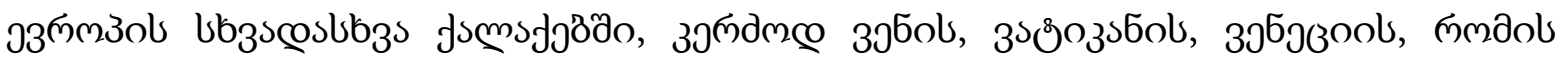

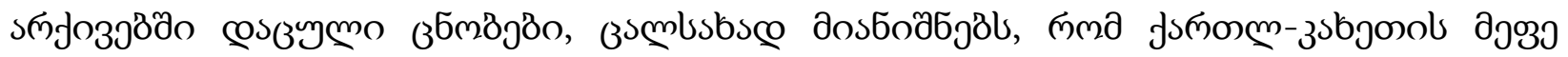

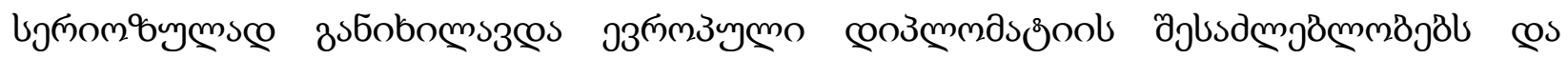

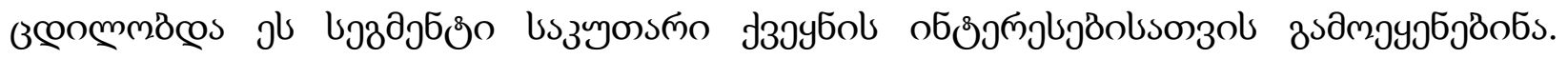

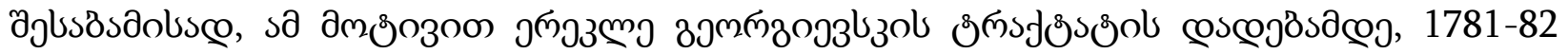

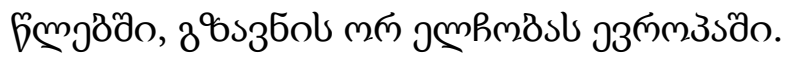

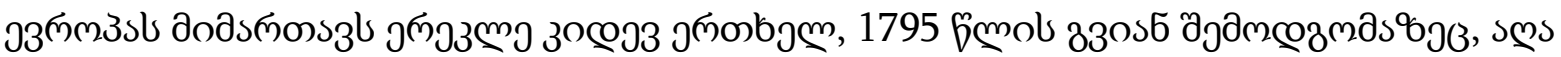

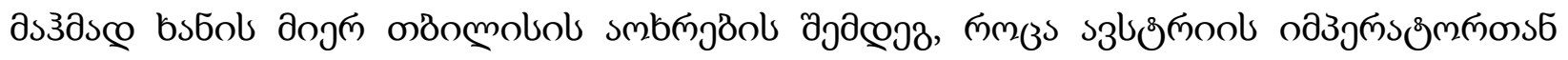

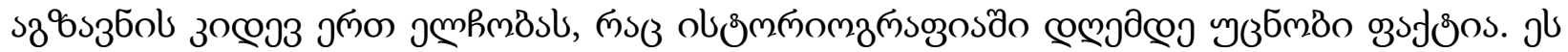

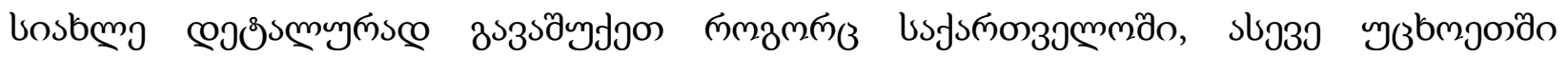

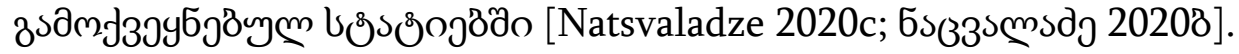

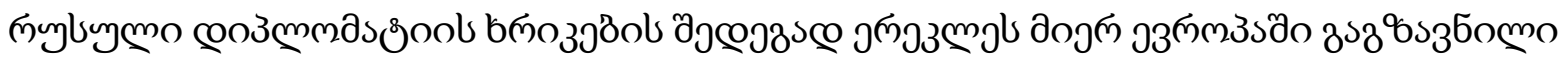

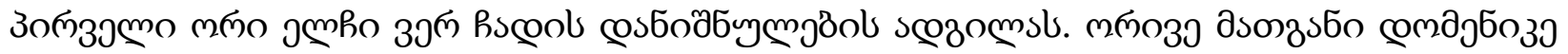

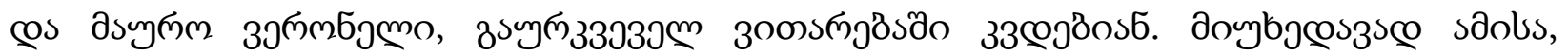

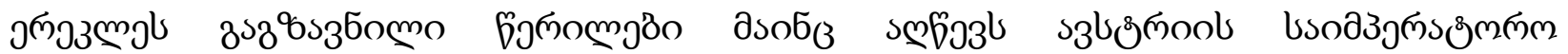

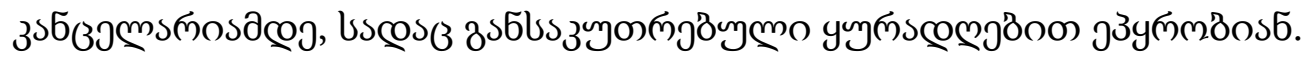

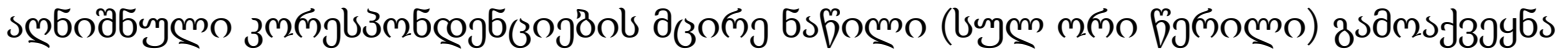

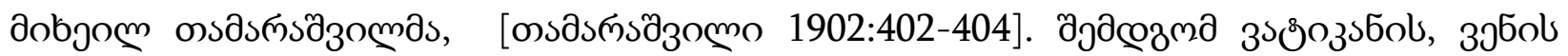

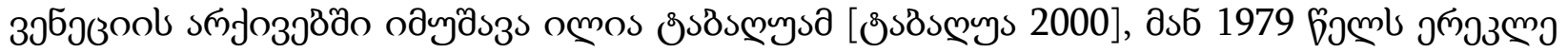

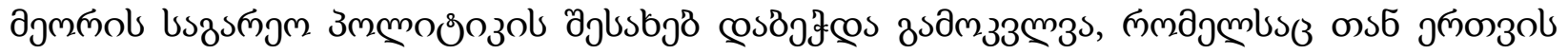

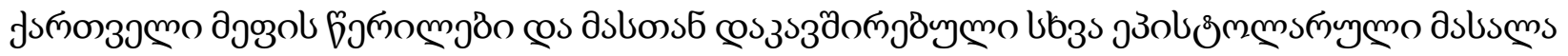
[ös8smys 1979].

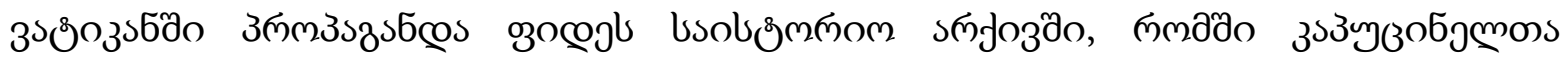

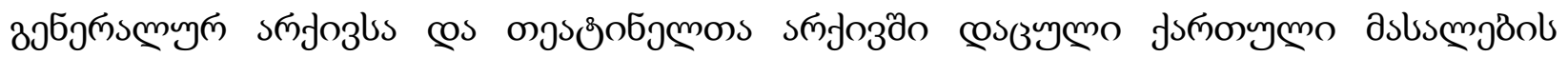

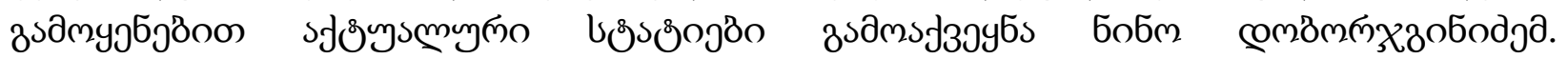

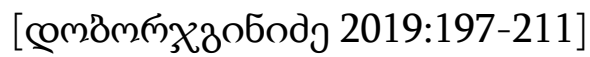

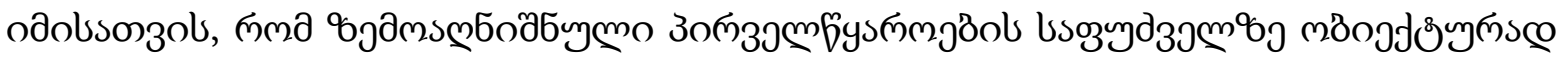

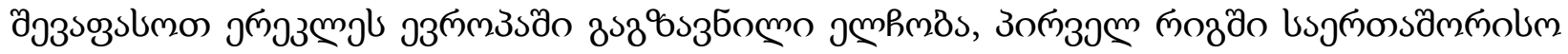

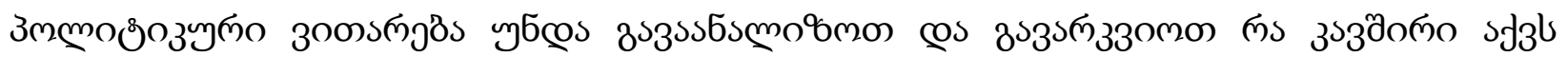

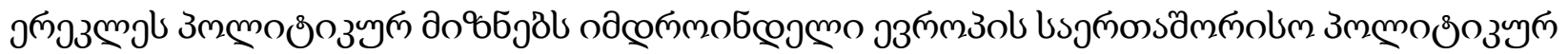

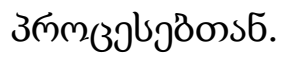

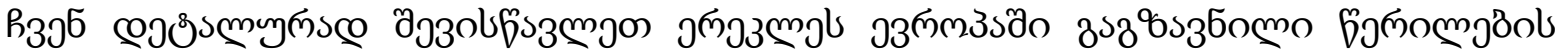

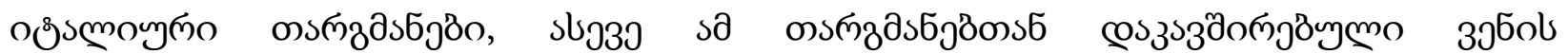

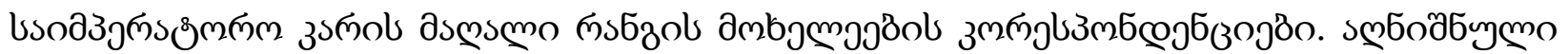

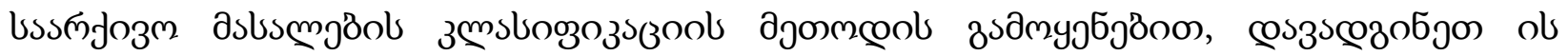

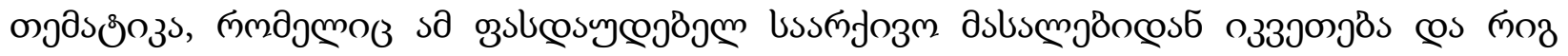




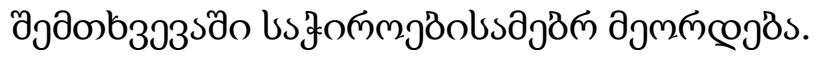

j๓

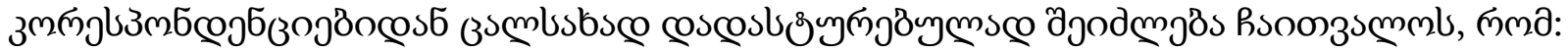

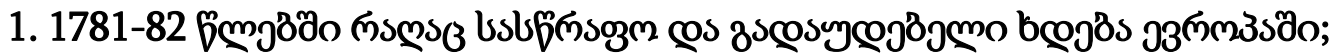

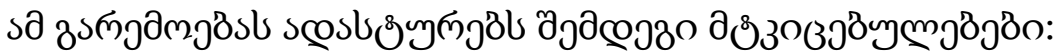

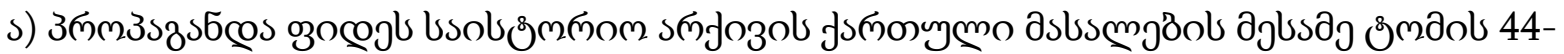

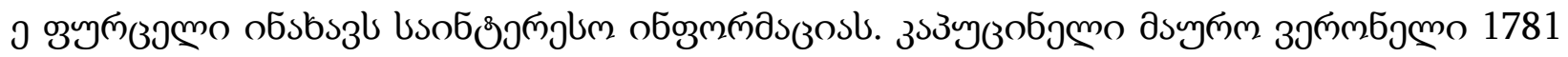

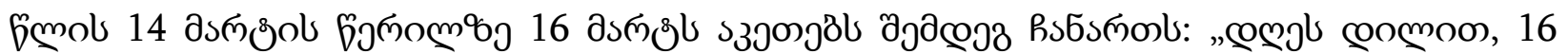

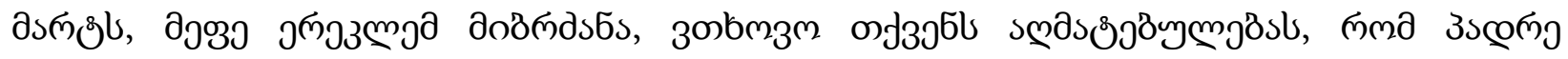

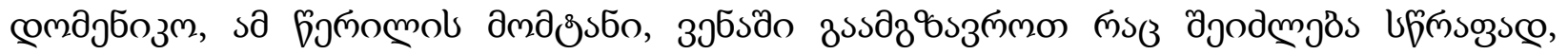

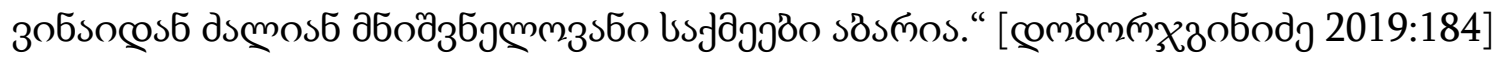

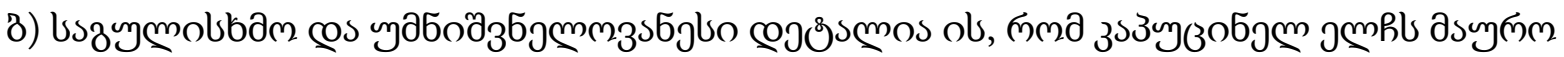

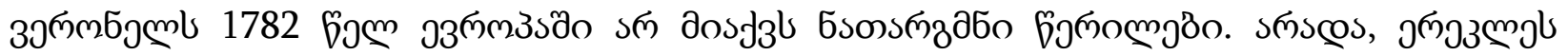

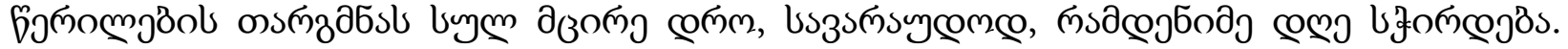

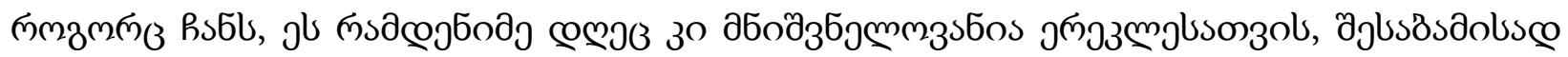

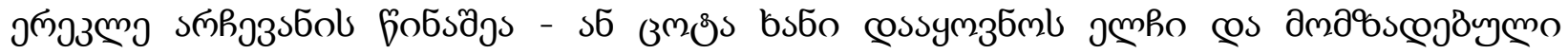

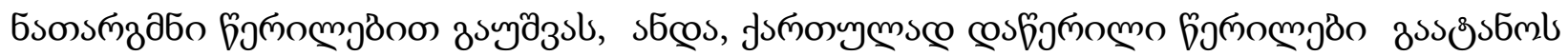

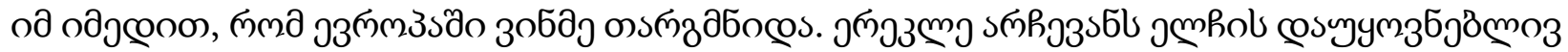

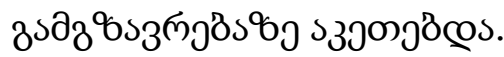

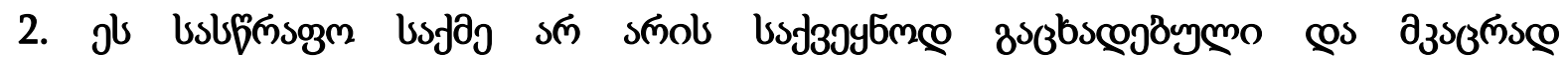

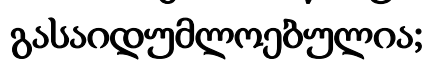

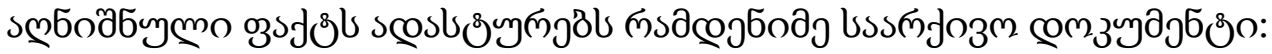

s) дзупм зэкмбј

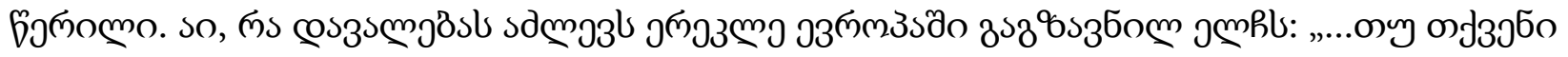

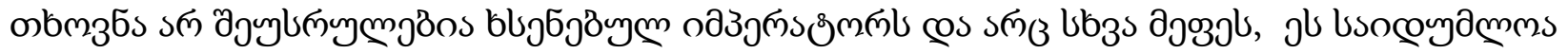

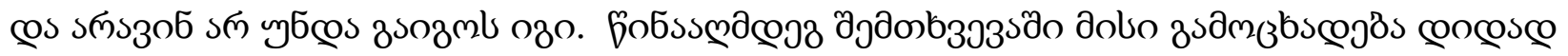

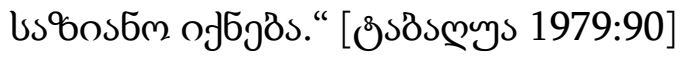

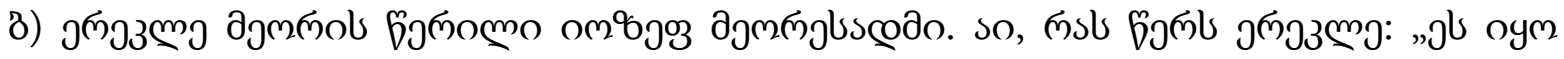

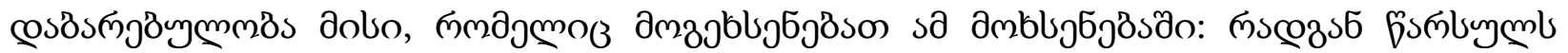

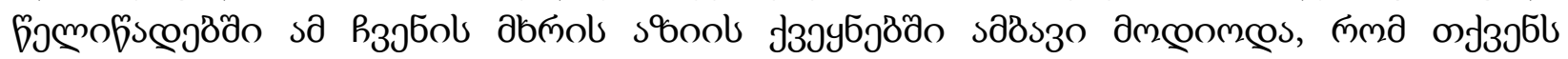

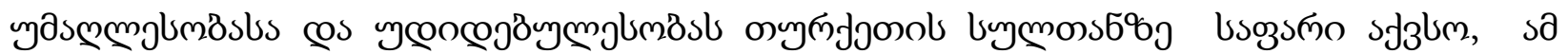

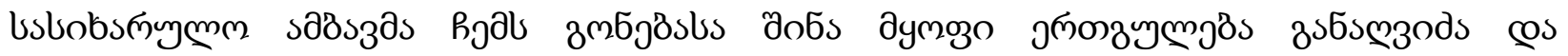

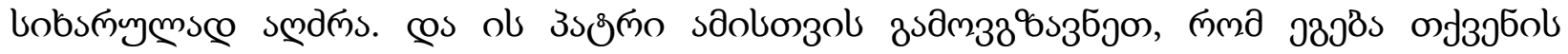

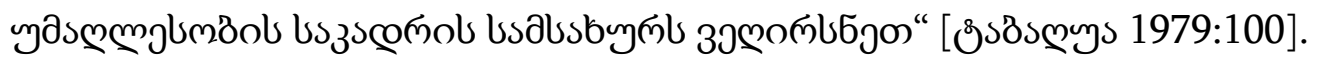

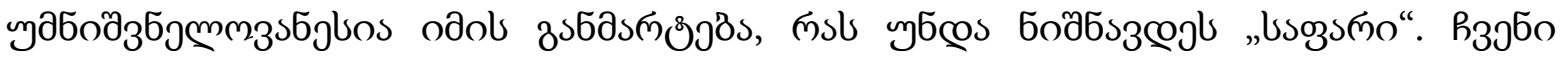

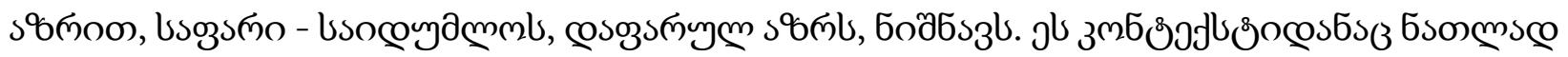

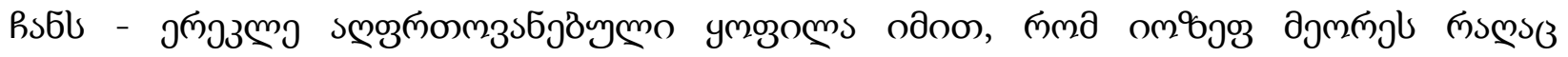

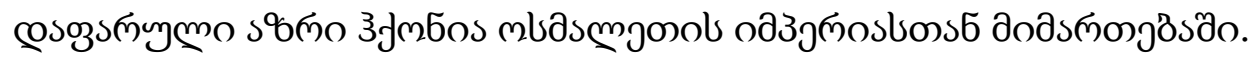

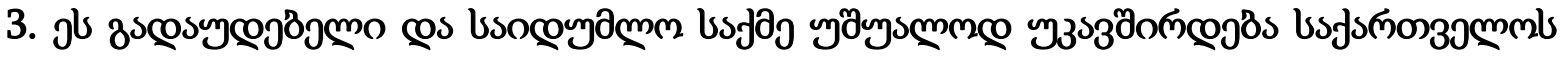

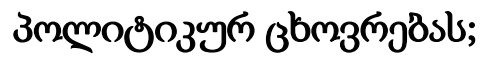

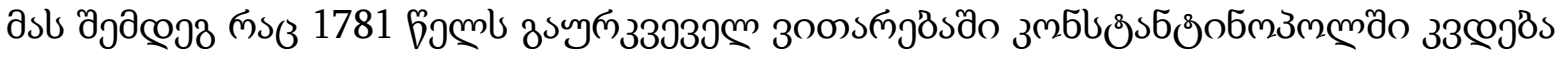




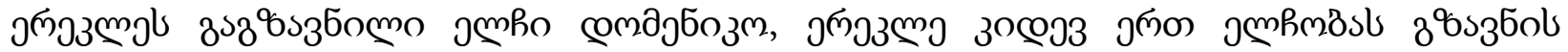

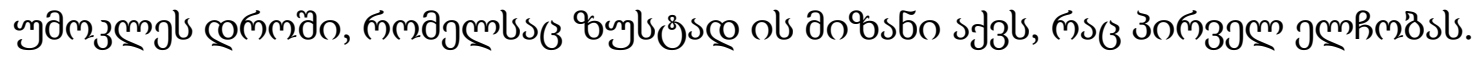

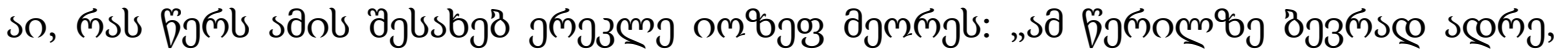

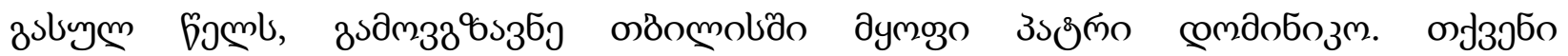

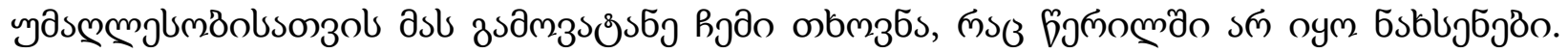

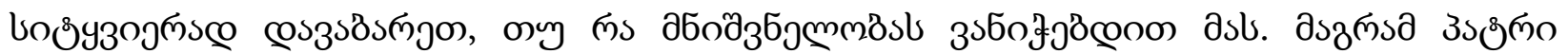

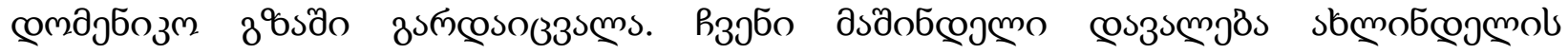
jobsösaobos." [8̊söspys 1979:104]

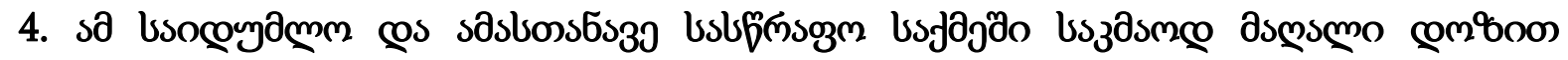

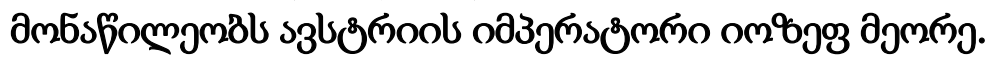

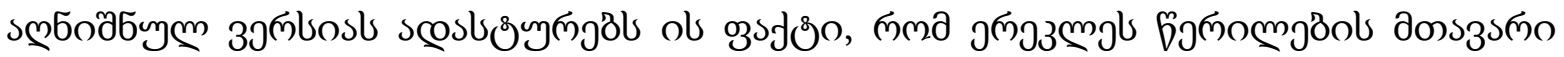

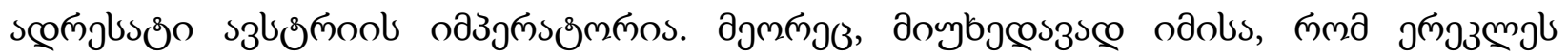

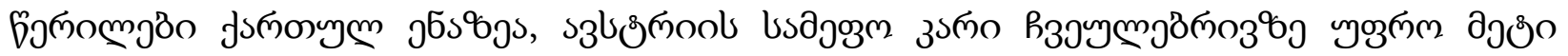

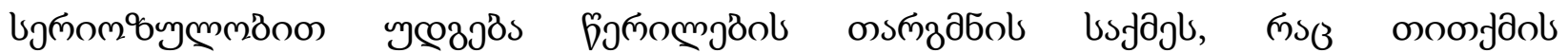

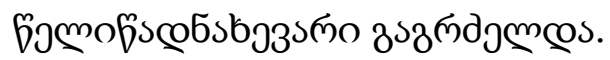

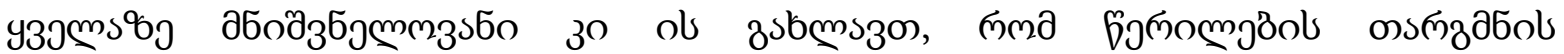

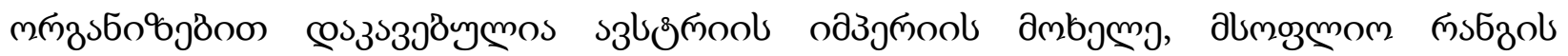

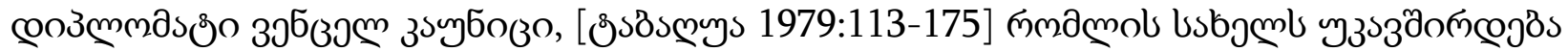

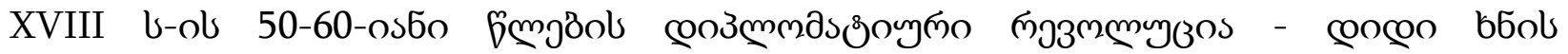

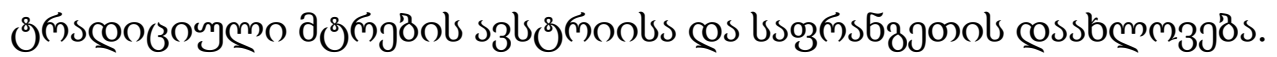

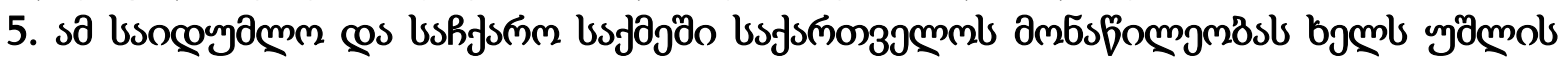

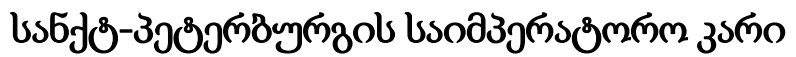

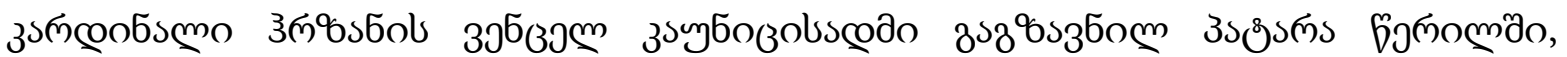

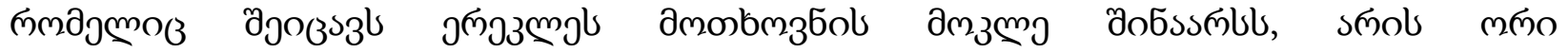

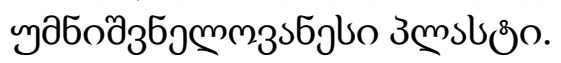

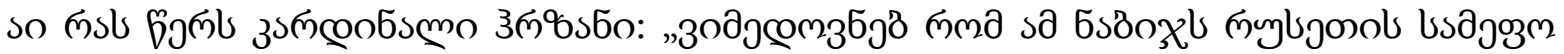

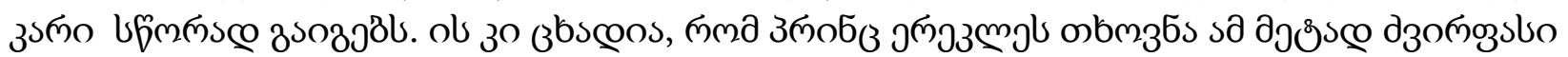

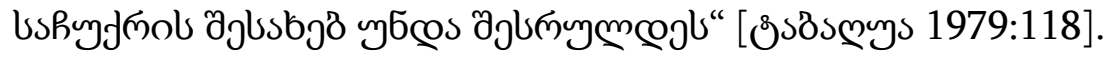

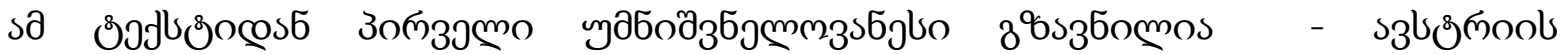

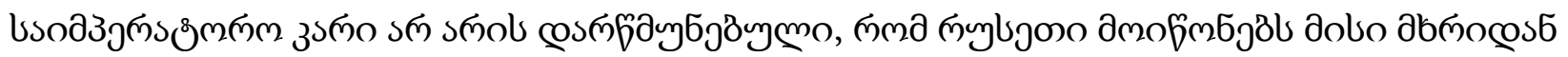

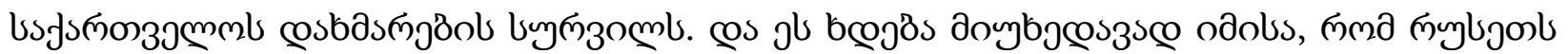

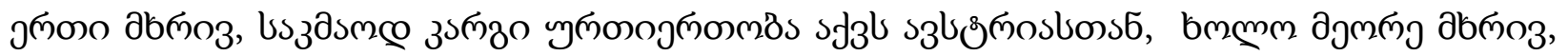

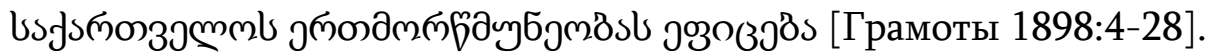

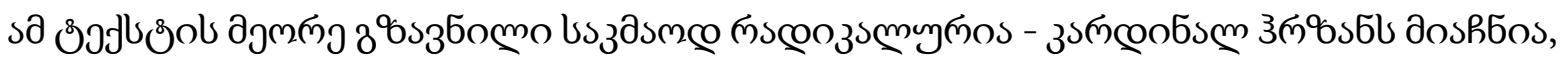

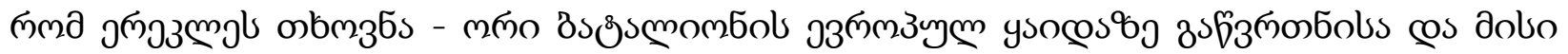

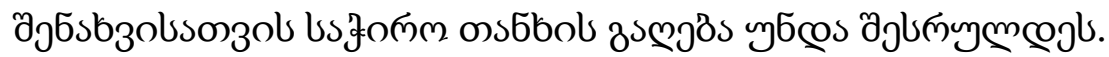

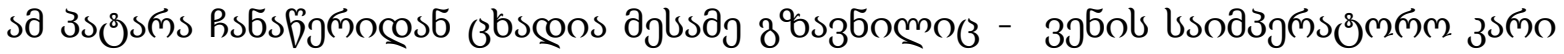

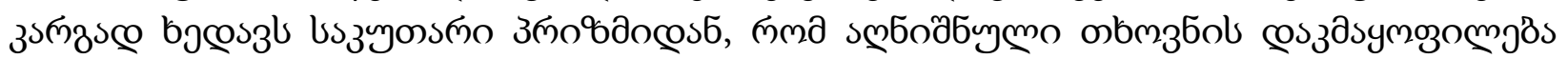

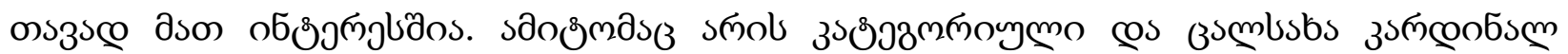

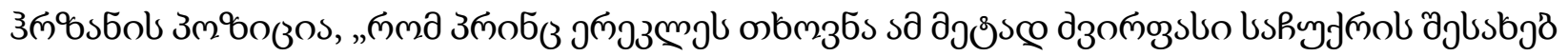

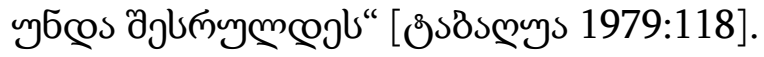




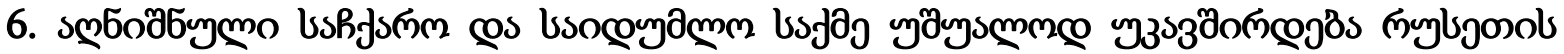 oazjnosl.}

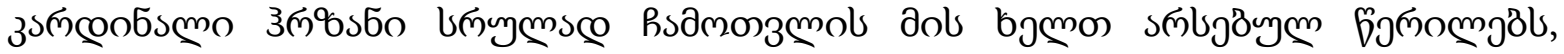

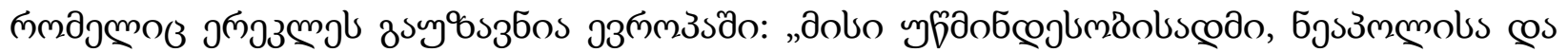

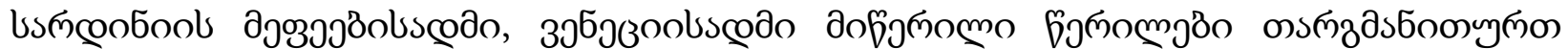

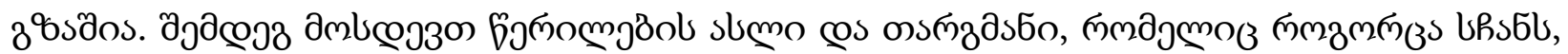

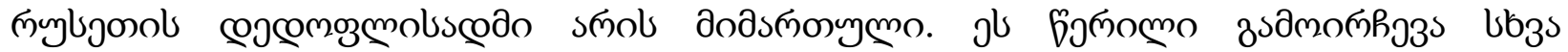

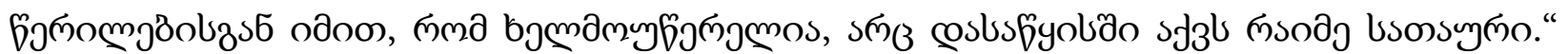
[8s8ssmys 1979:119]

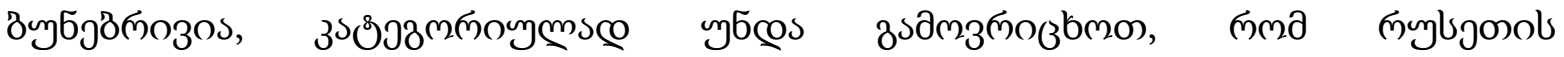

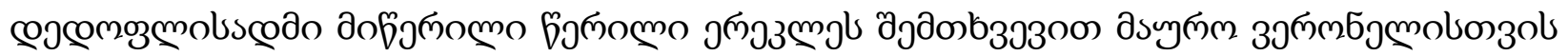

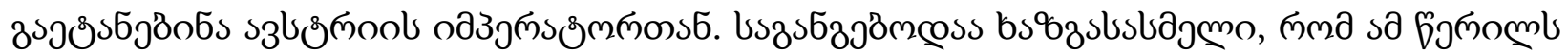

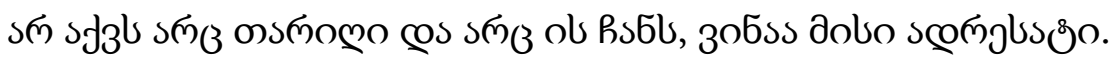

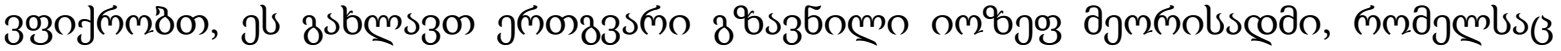

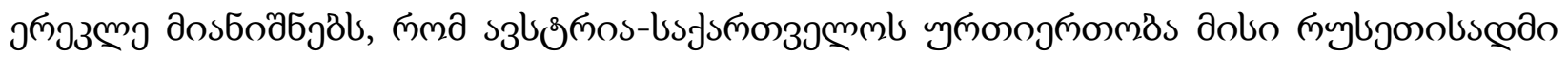

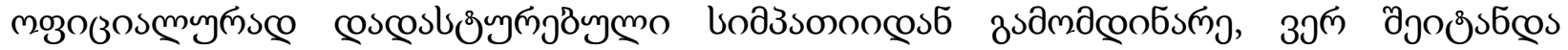

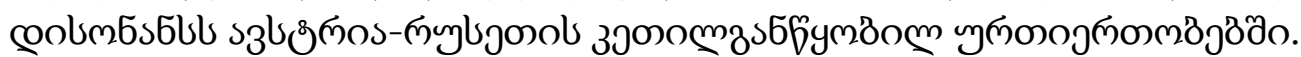

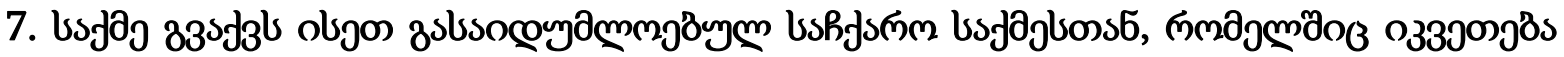

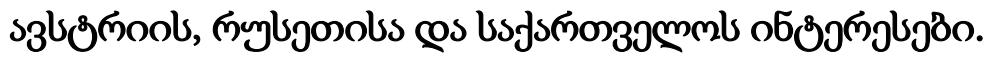

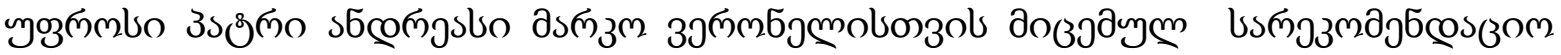

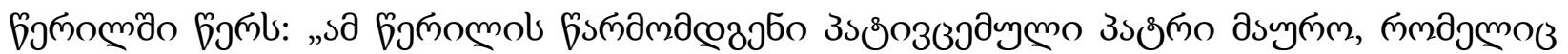

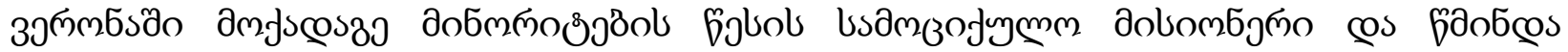

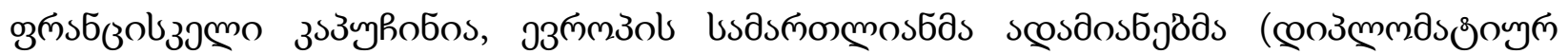

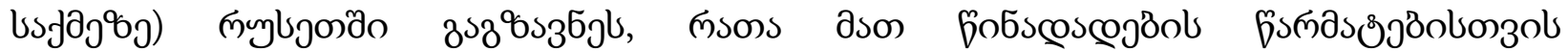

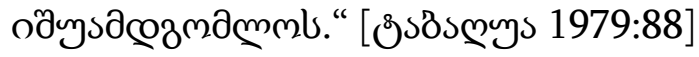

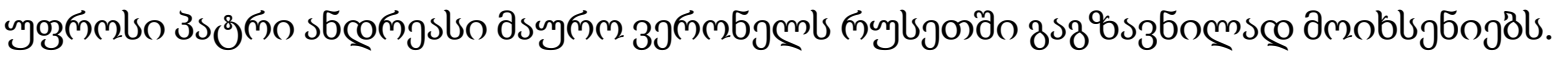

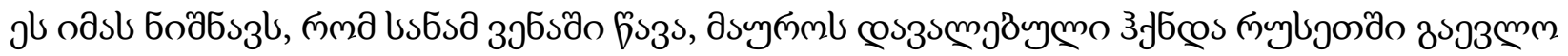
ды

8. j๓

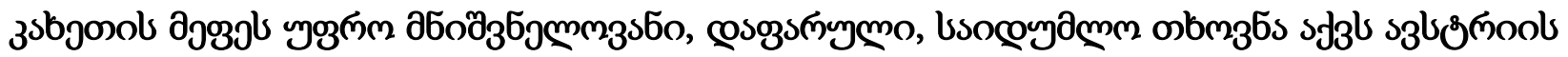

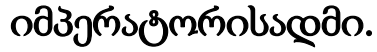

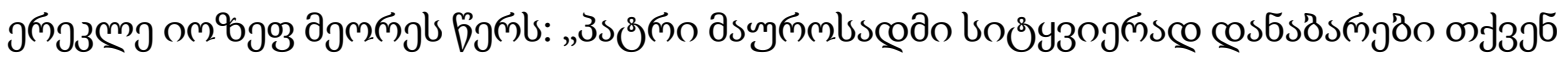

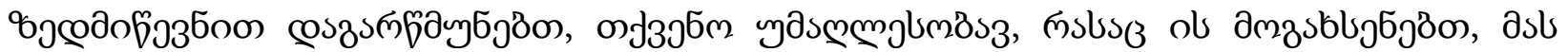

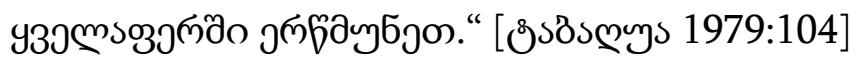

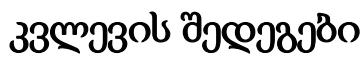

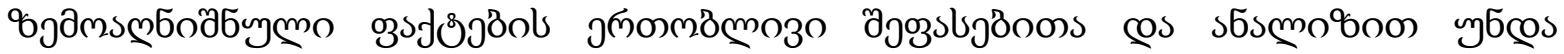

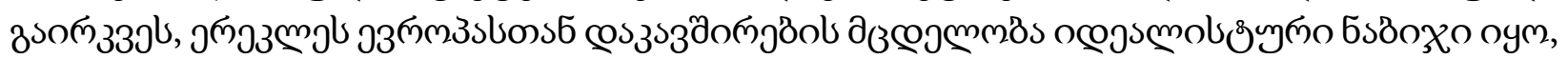

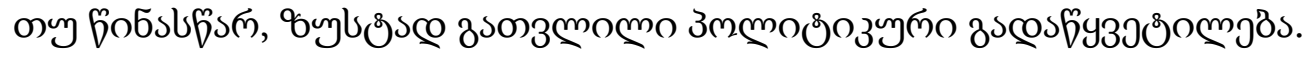

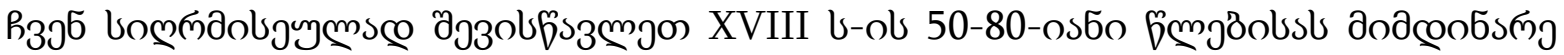

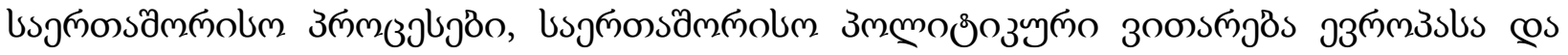




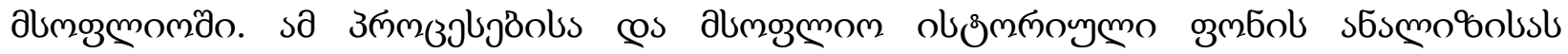

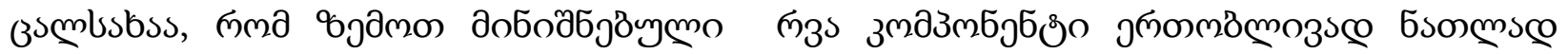

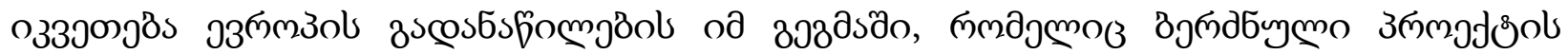

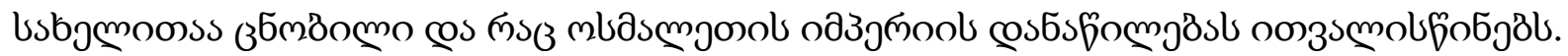

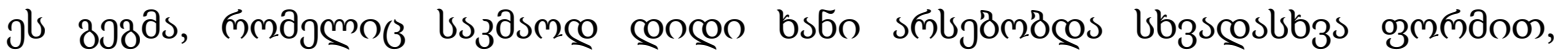

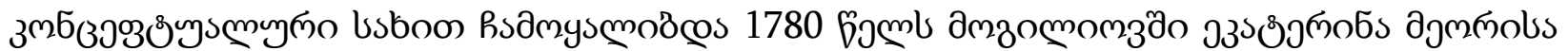

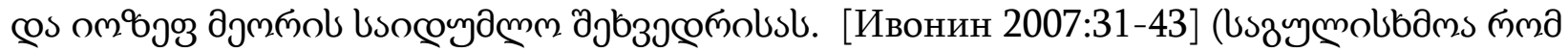

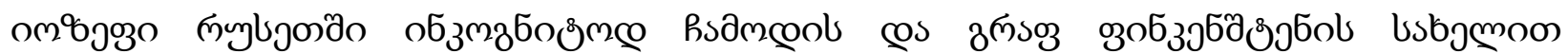

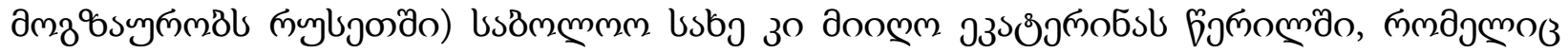

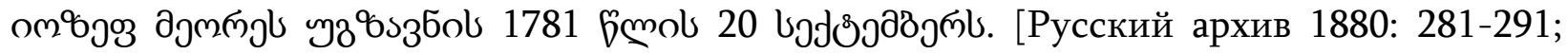
Arneth 1869:143-157]

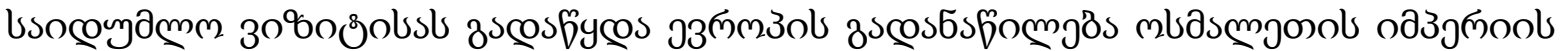

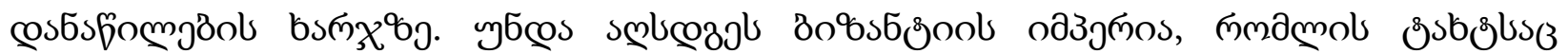

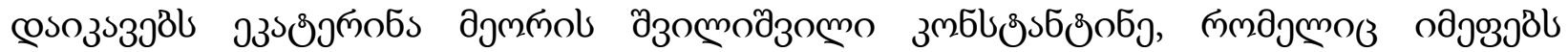

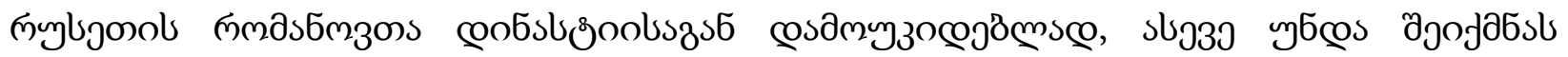

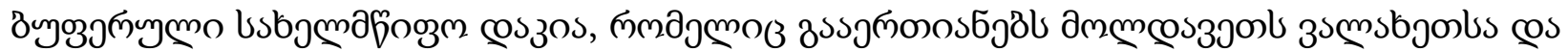

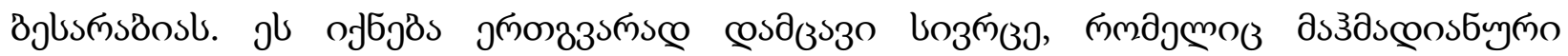

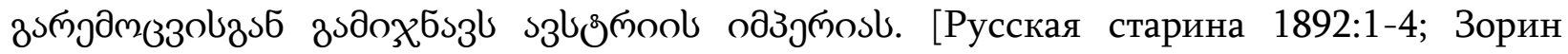
2001:35-37; Гриффитс 2013:352-360; Маркова 1986:5-11]

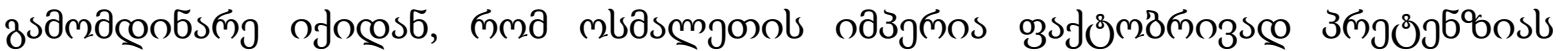

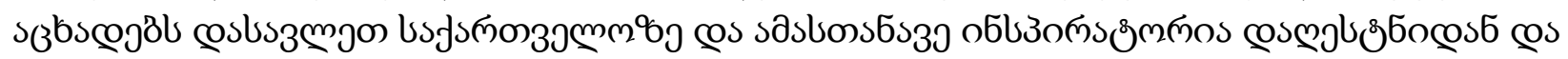

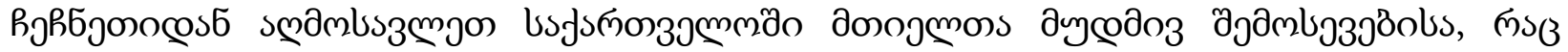

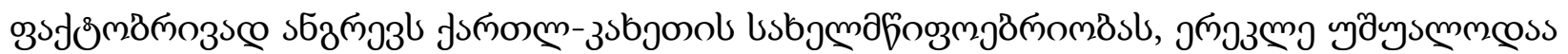

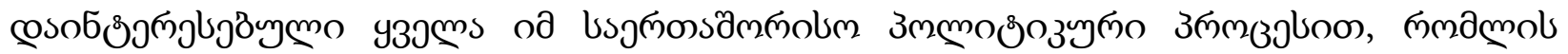

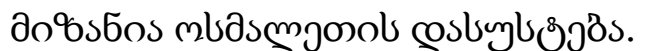

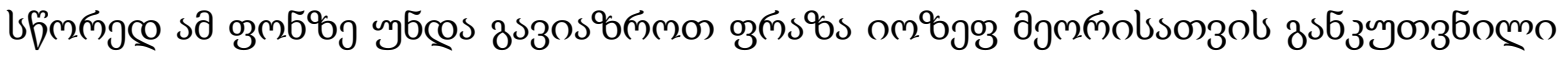

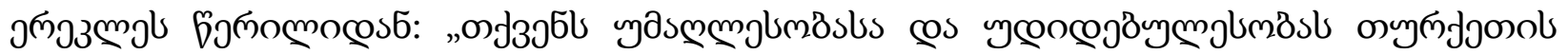

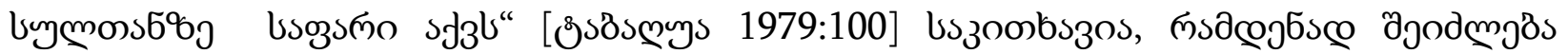

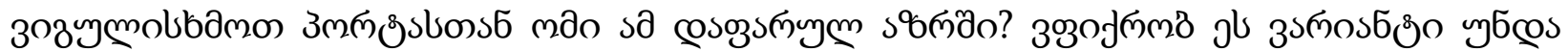

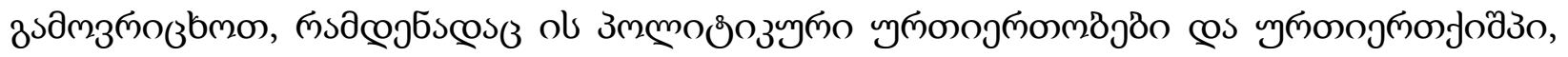

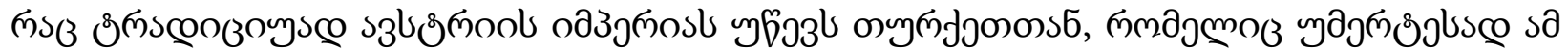

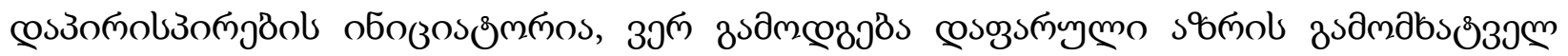

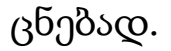

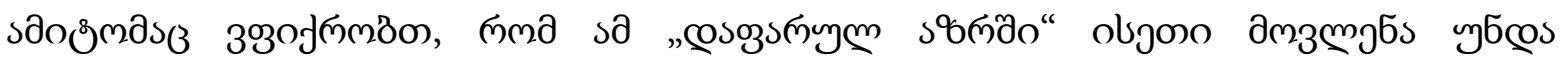

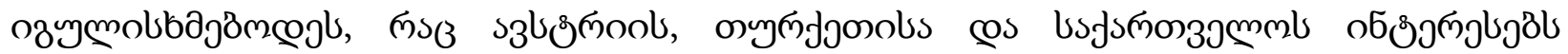

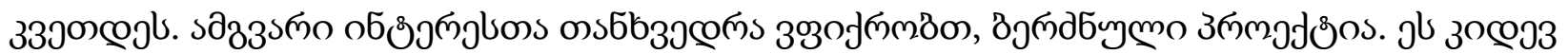

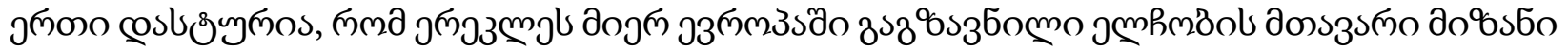

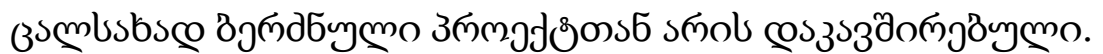

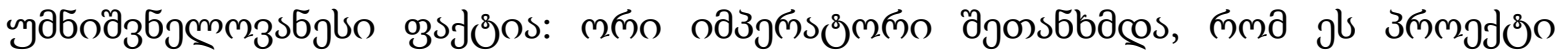

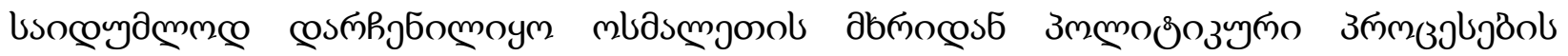

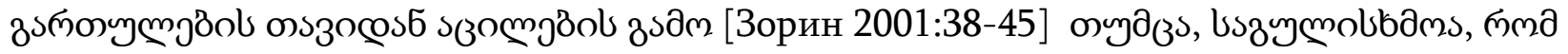




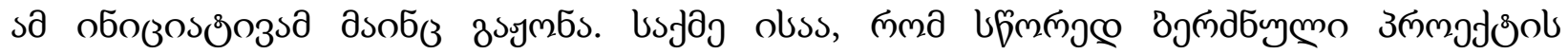

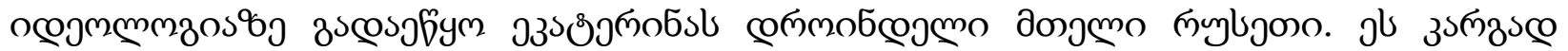

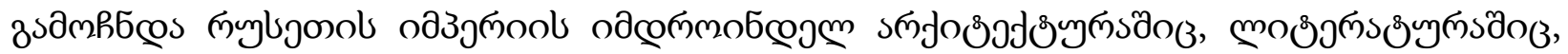

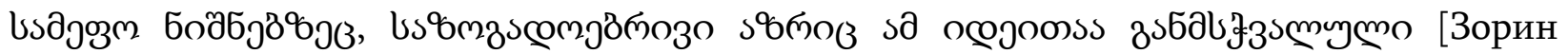

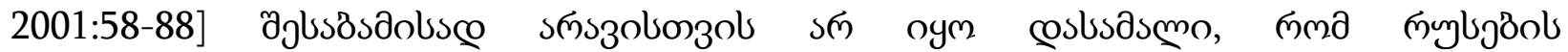

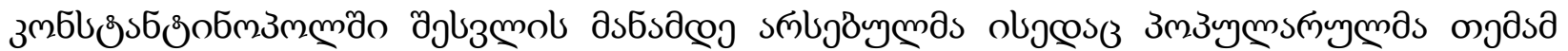

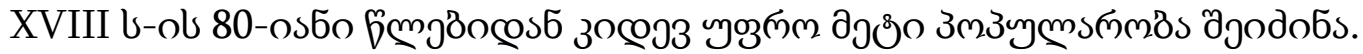

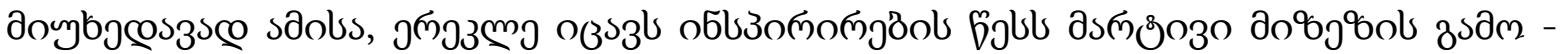

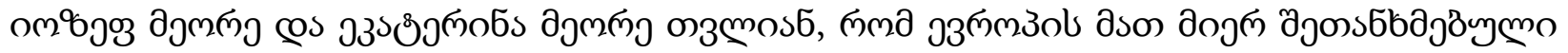

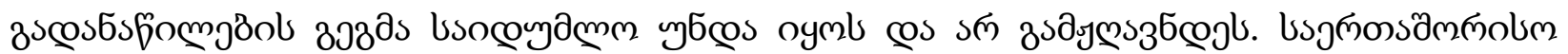

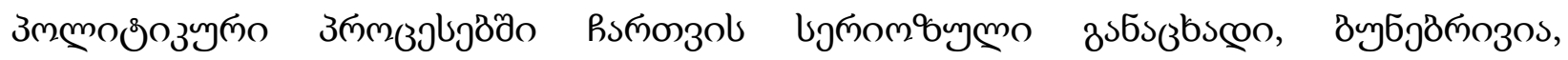

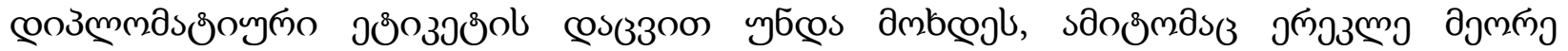

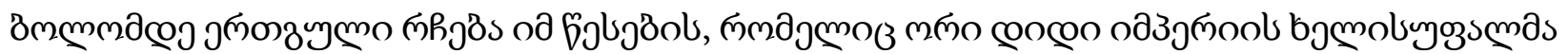
cosscozots.

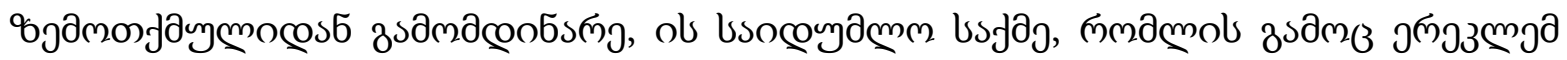
вง

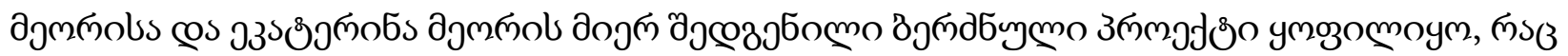

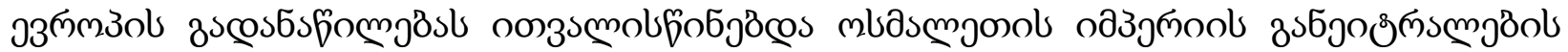
$8 \mathrm{bon}$.

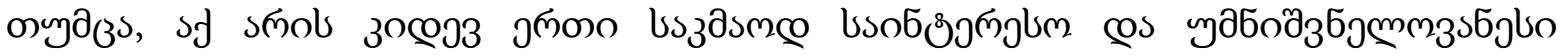

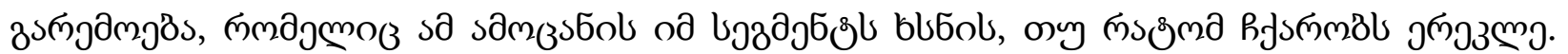

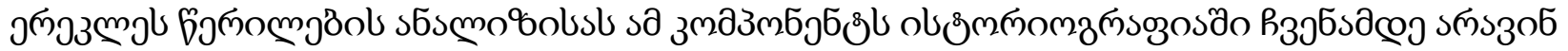

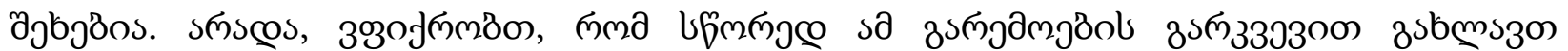

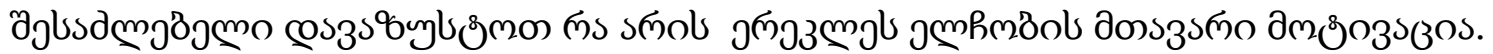

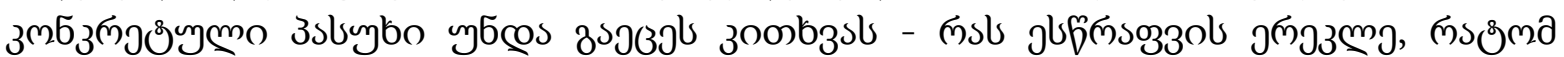

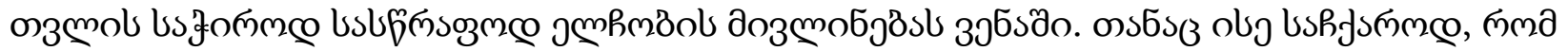

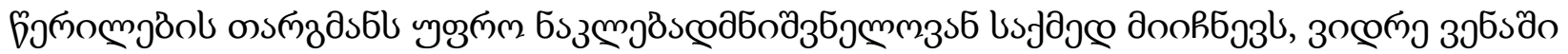
jemhol comm\%g hislzmsl.

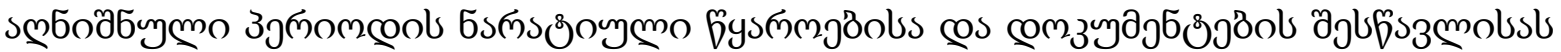

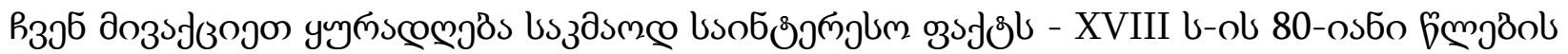

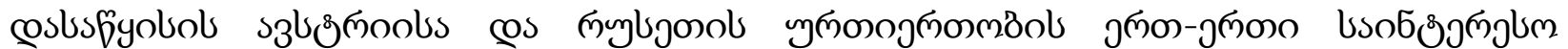

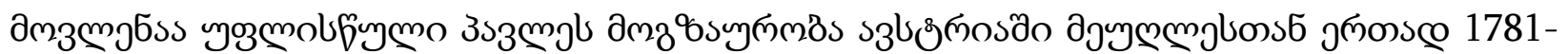
82 белдðо [Хаванова 2016:97; РИО 1872:70-97].

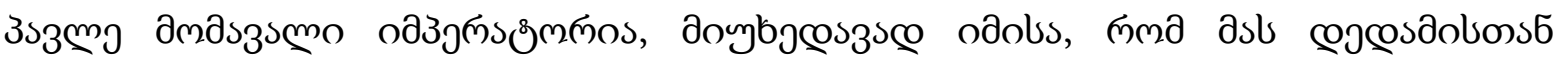

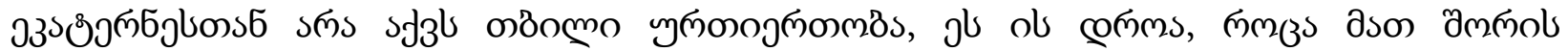

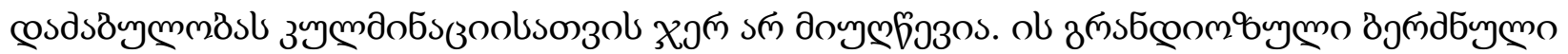

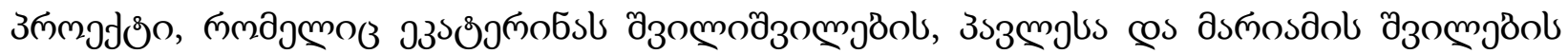

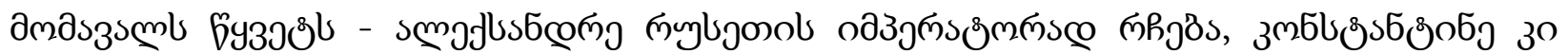

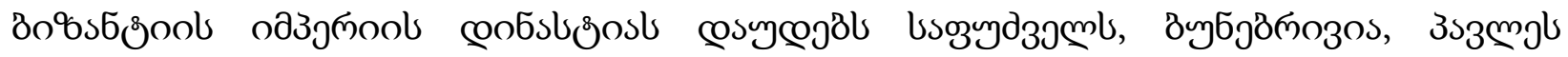

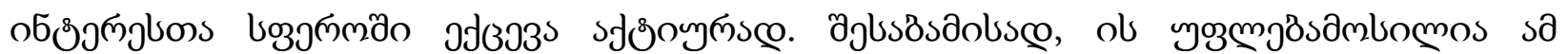

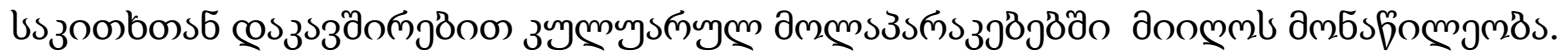




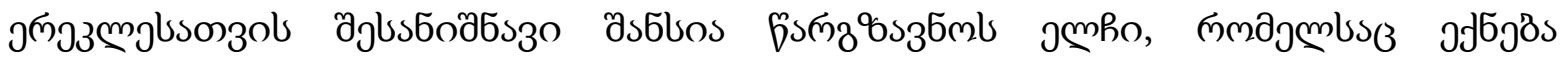

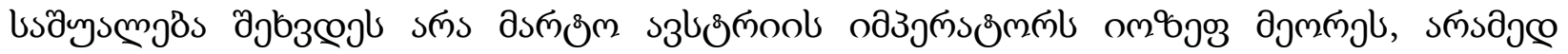

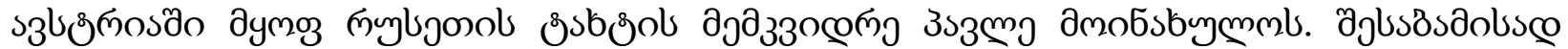

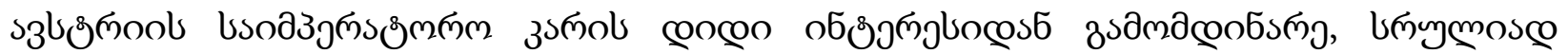

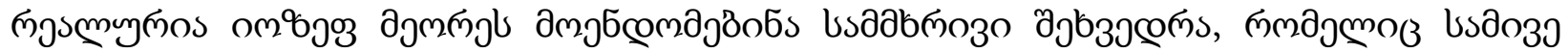

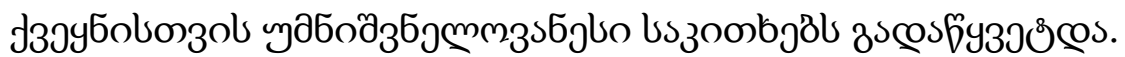

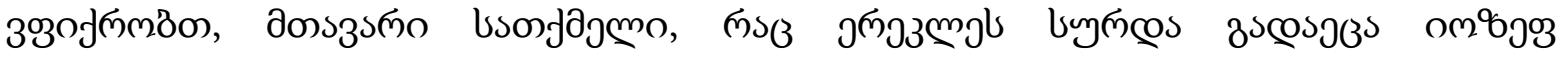

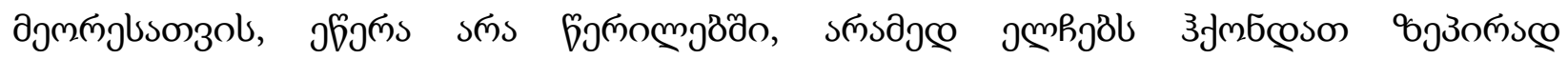

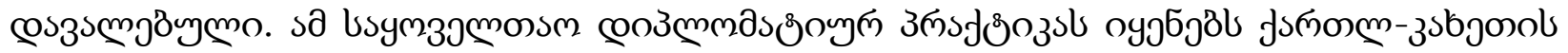

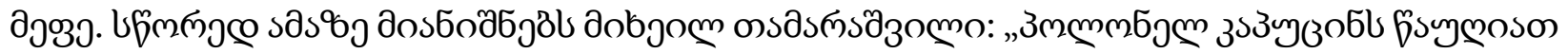

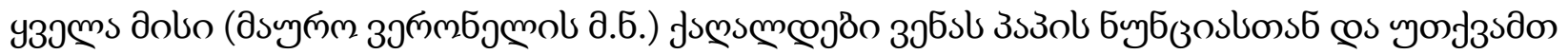

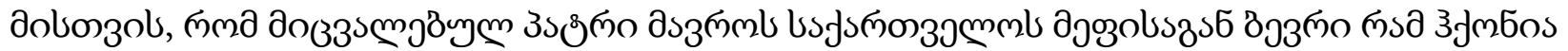

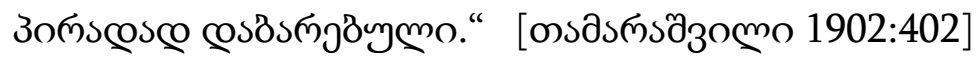

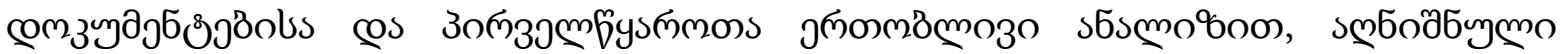

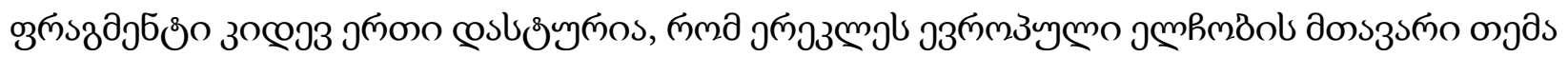

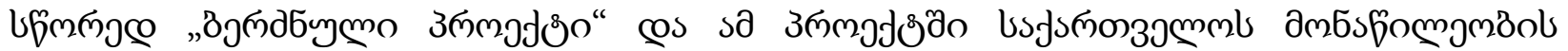
ls zootbos.

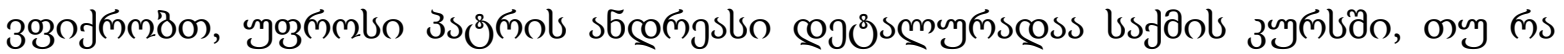

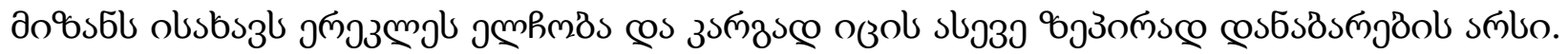

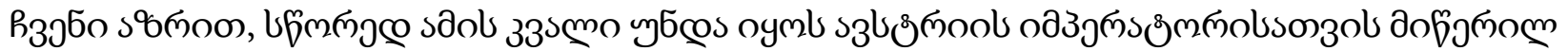

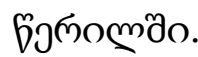

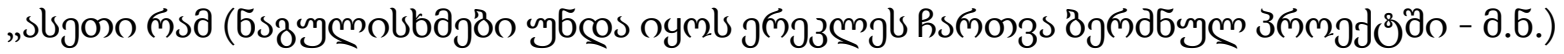

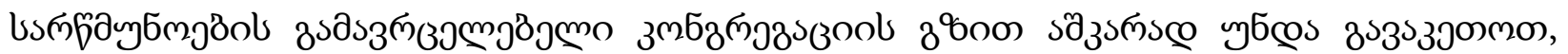

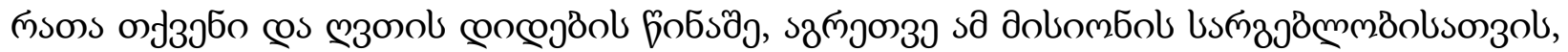

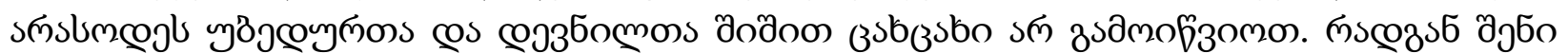

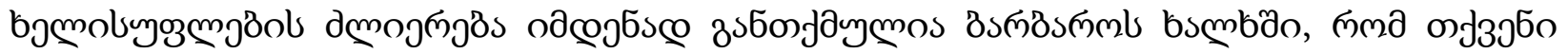

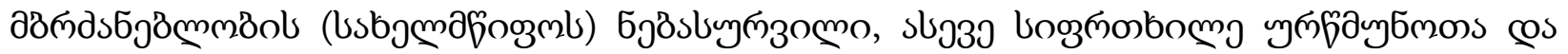

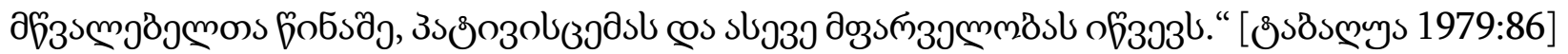

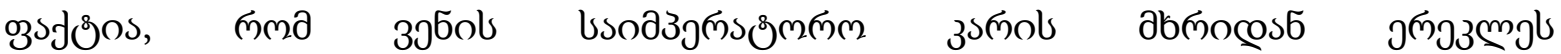

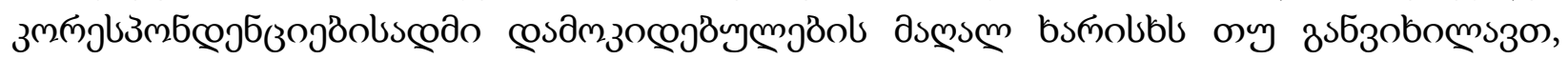

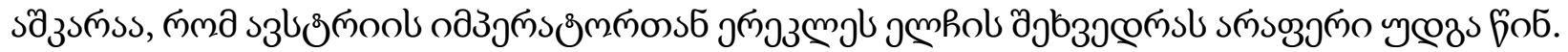

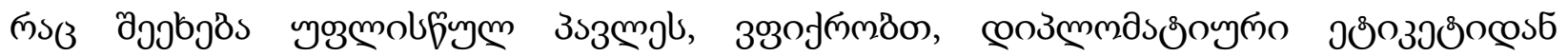

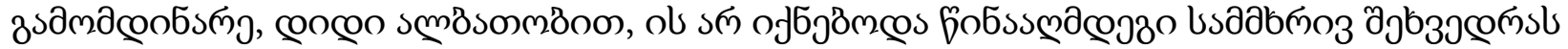
csonstbajöm@s.

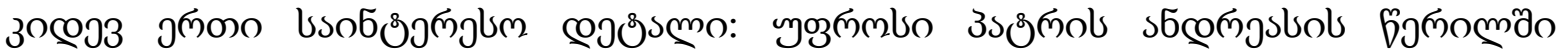

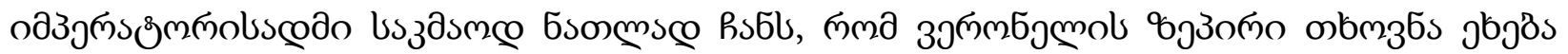

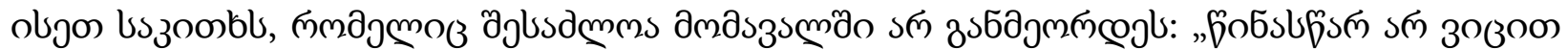

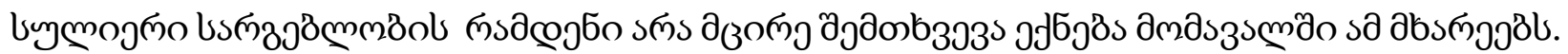

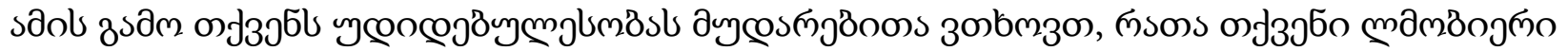

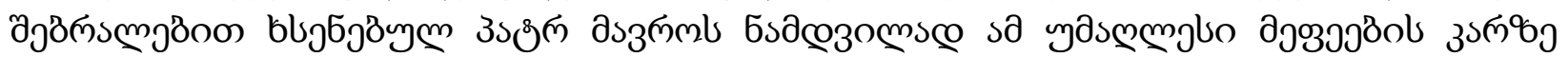

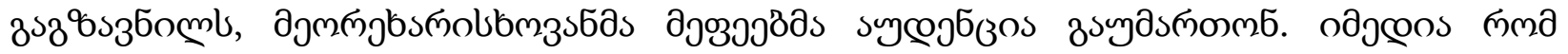




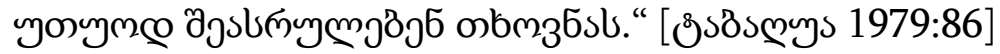

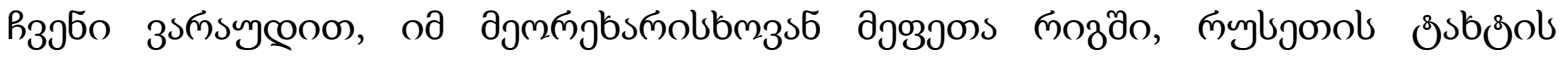

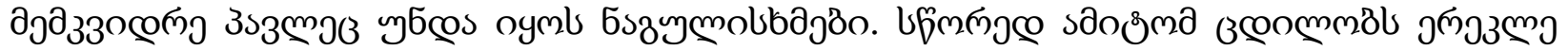

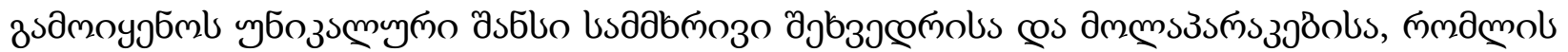

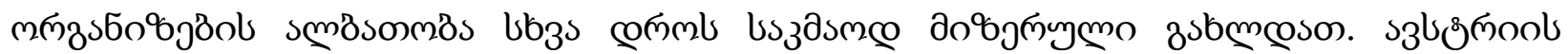

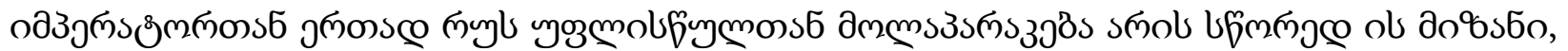

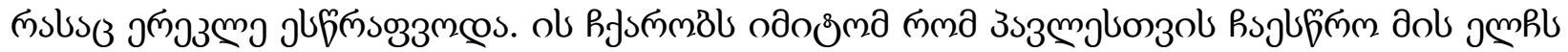

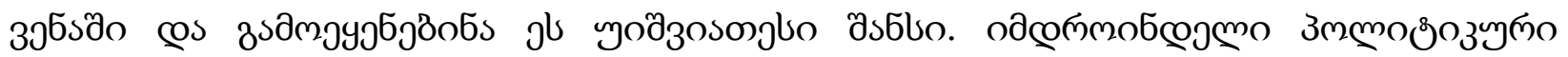

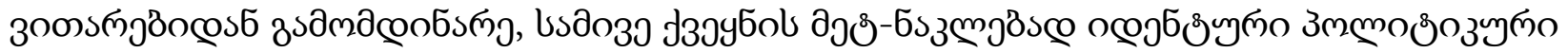
обөэ

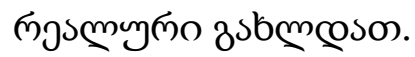

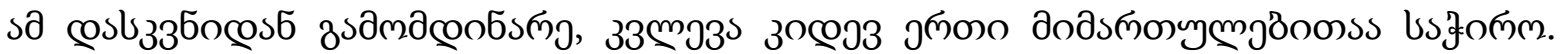

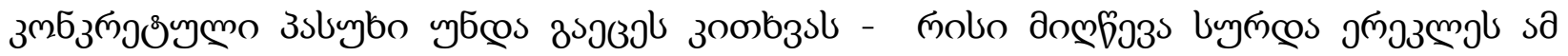

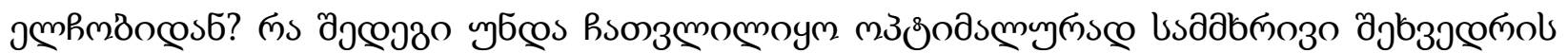

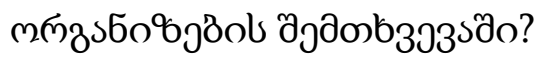

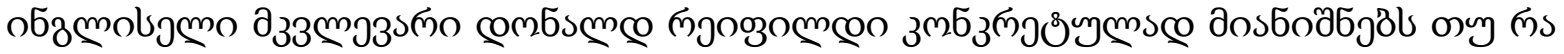

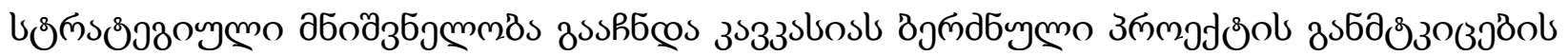

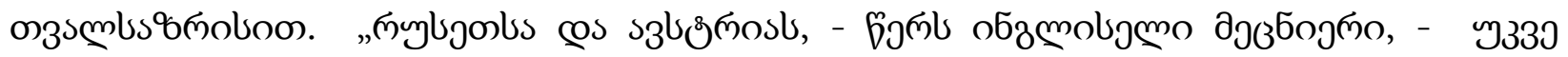

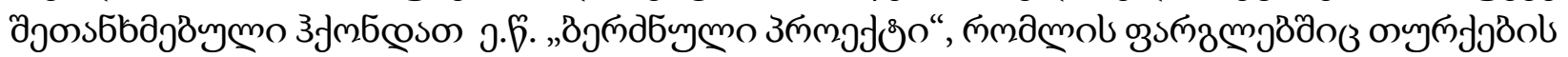

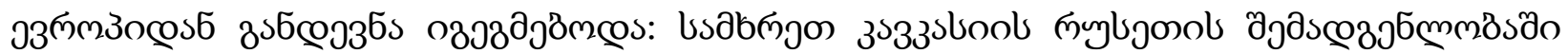

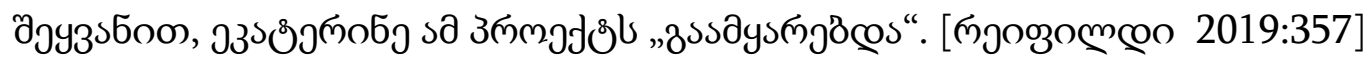

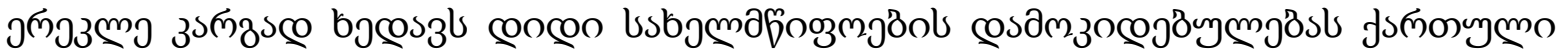

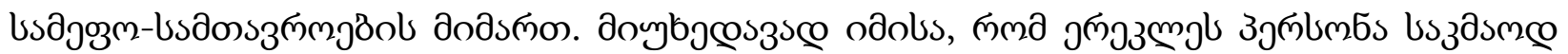

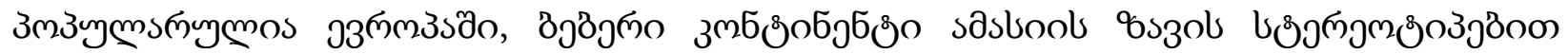

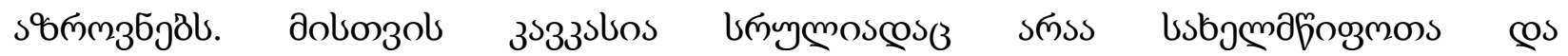

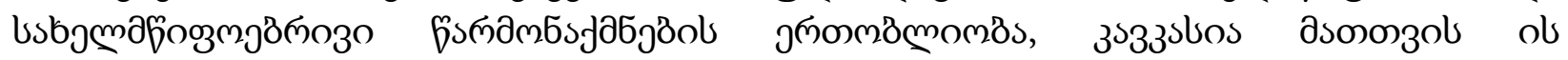

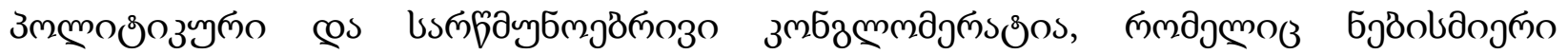

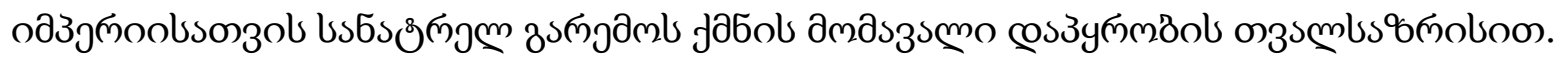

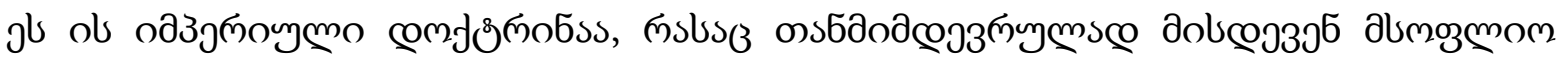

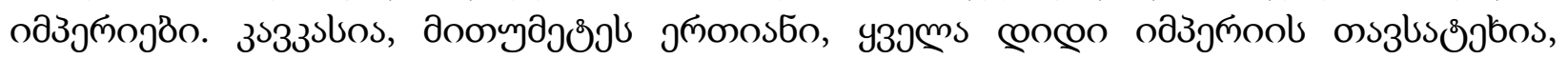

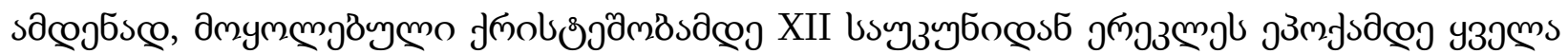

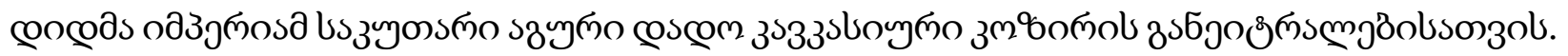

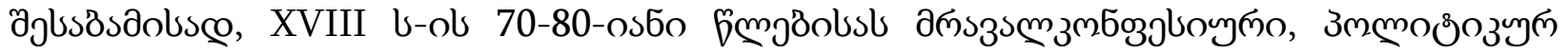

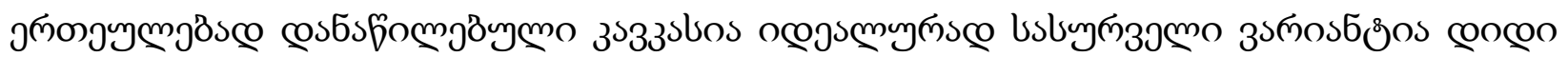

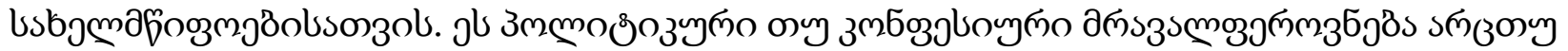

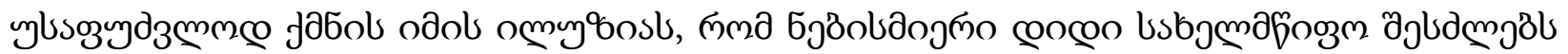

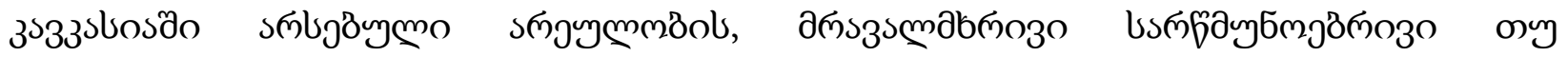

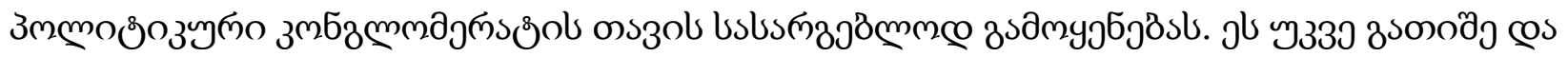

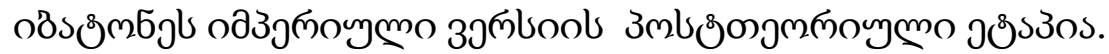

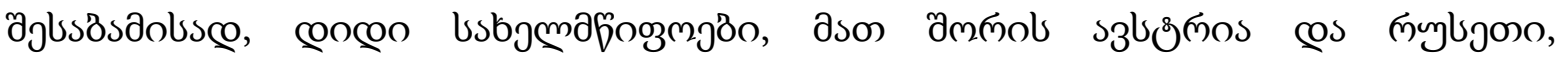

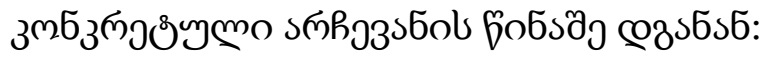




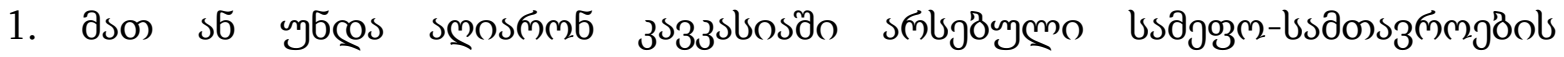

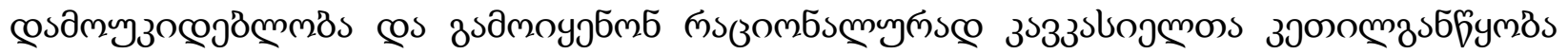

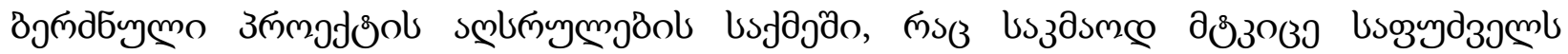

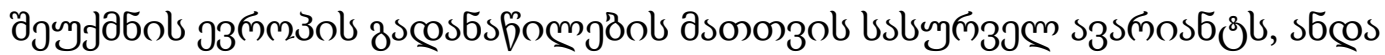

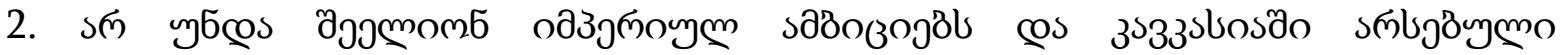

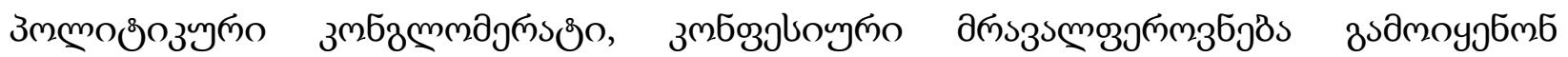

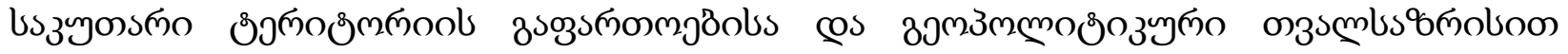

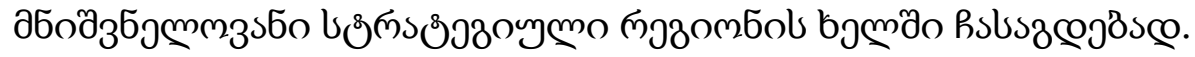

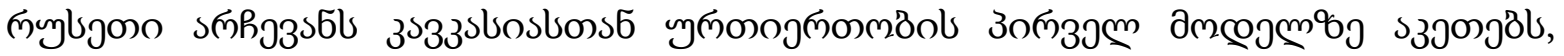

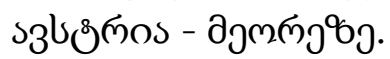

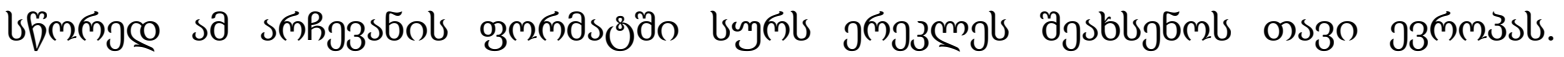

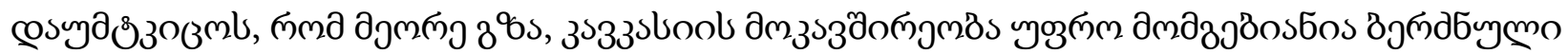

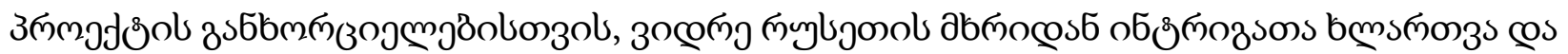

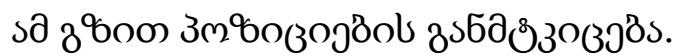

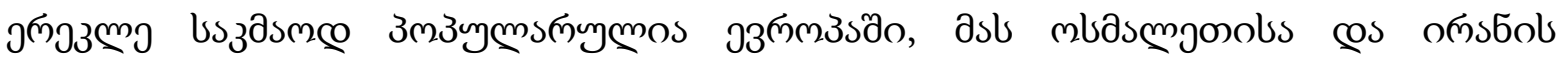

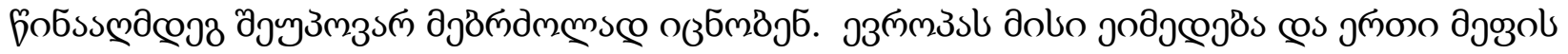

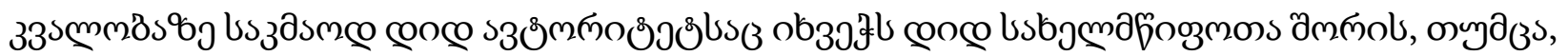

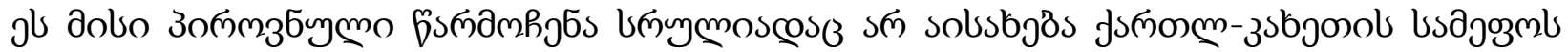

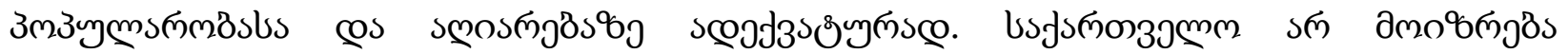

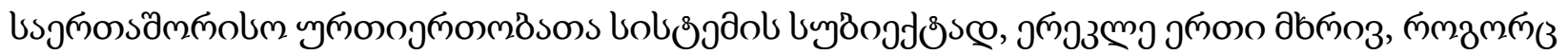

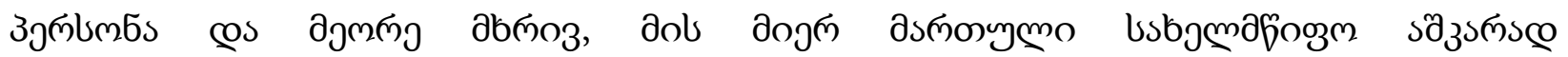

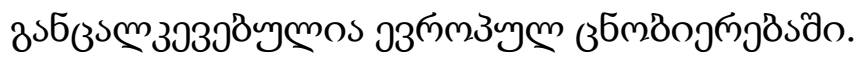

\section{cost $336 s$}

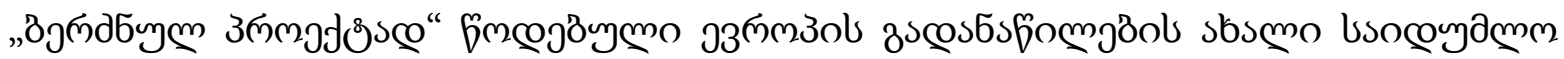

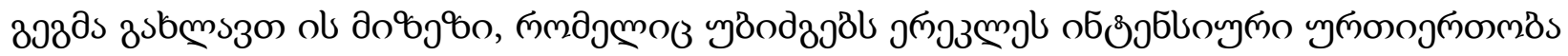

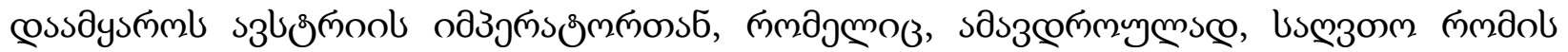

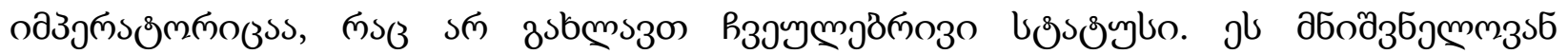

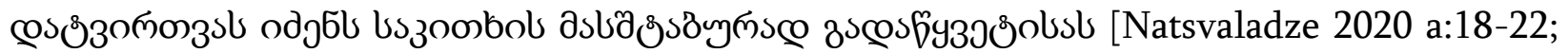
Natsvaladze 2020 b:28-41].

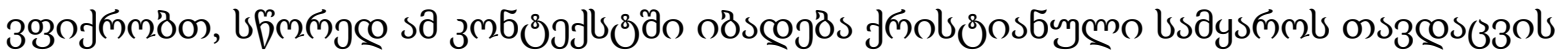

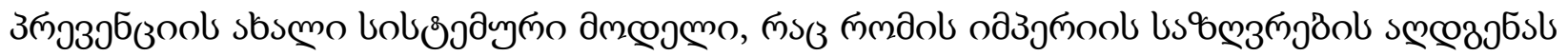

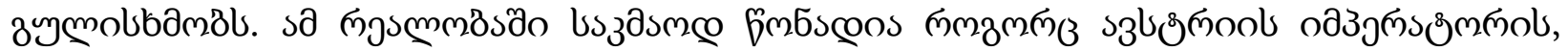

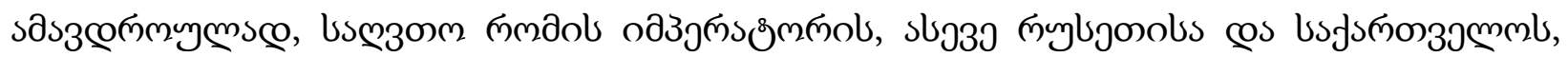

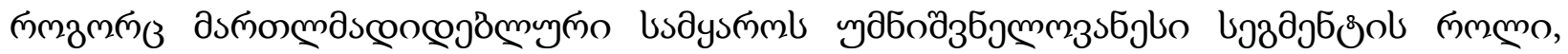

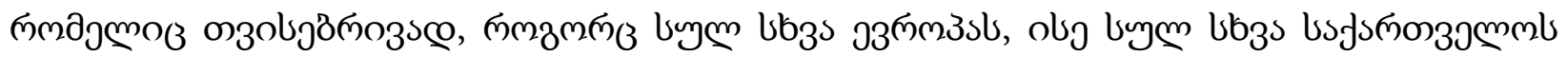

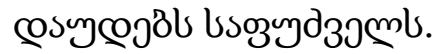

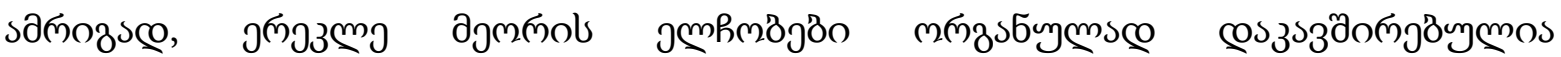

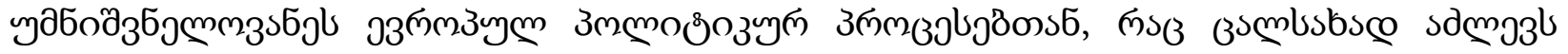

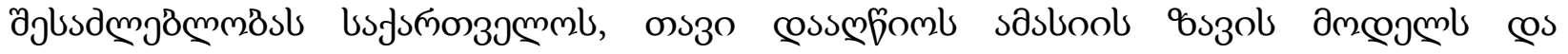

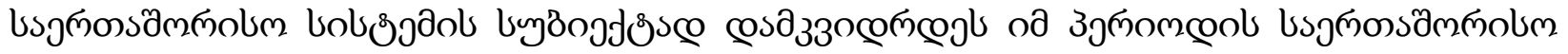




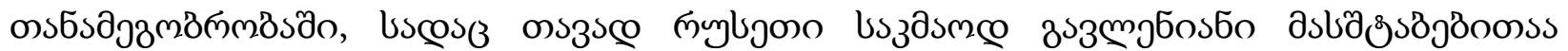

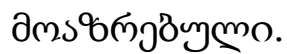

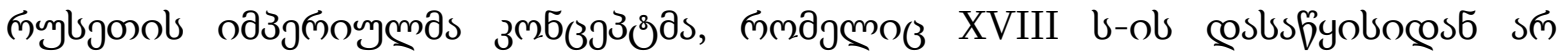

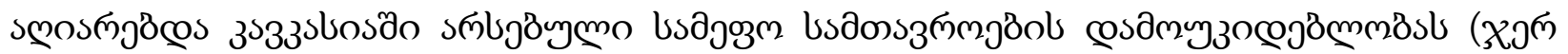

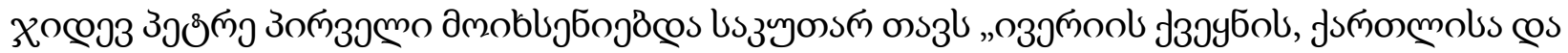

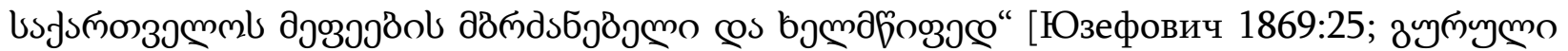

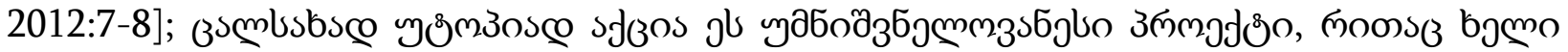

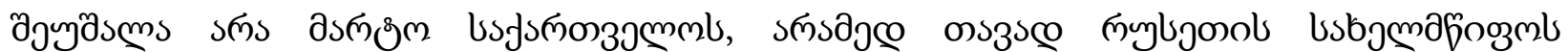

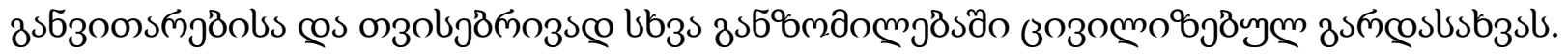

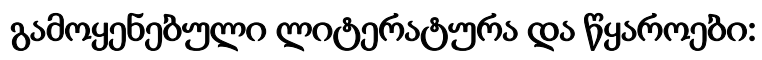

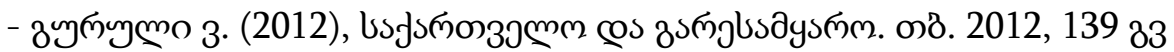

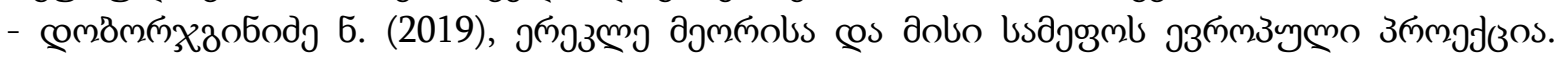

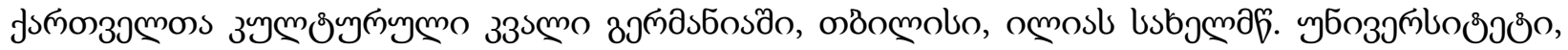
2019. 83 166-218

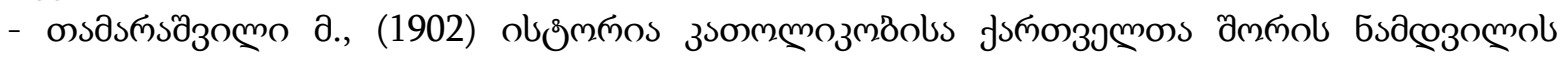

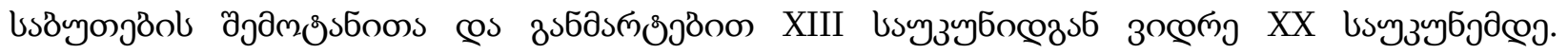

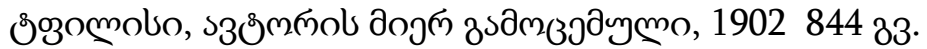

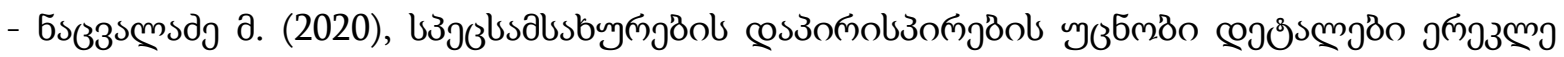

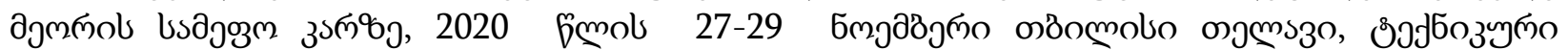

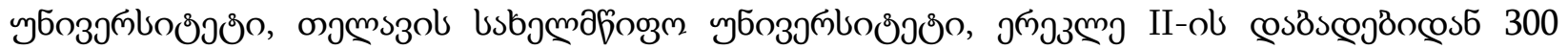

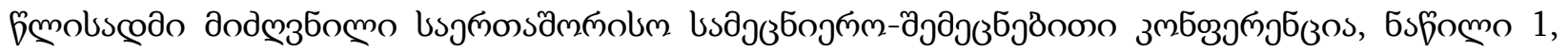

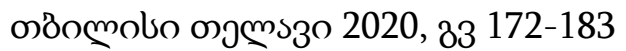

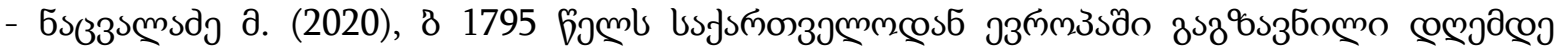
э

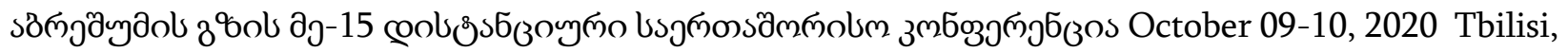
Georgia, 33. 234-244

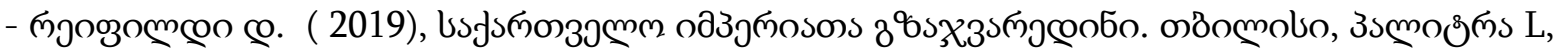
2019. 676 33.

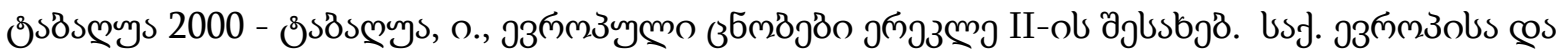

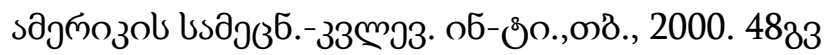

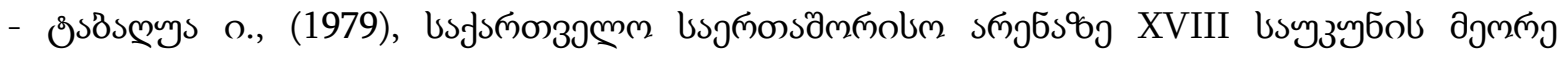

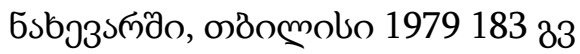

Arneth 1869 - Joseph II und Katharina von Russland. Ihr Briefwechsel, hrsg. von Alfred, Ritter von Arneth, Wien, 1869 s 446

Natsvaladze 2020 a - Natsvaladze M. Georgia and the Secret Project for Redistribution Europe 7080s of the 18th century, LXXVI International Scientific Review of the Problems and Prospects of Modern Science and Education, (Boston. USA. - 23 December, 2020) p 38-46

Natsvaladze 2020b - Natsvaladze M. Greek Project - Clue to the History of Georgia 50-90-ies of XVIII Century. XXIII International Scientific and Practical Conference Social and Economic Aspects of Education in Modern Society. Vol.1, November 25, 2020, Warsaw, Poland. pp 38-43 
Natsvaladze 2020c - Natsvaladze M. Sensational Unknown Facts from Georgian Diplomacy of 90ies of XVIII Century, International Journal of Innovative Technologies in Social Science. No 7(28) (2020) p.77-85

Natsvaladze 2020d - Natsvaladze M. Explanation of one conceptual subtext of a "Greek Project", XI International Conference. Science and Practice: a new level of integration in the modern world, Scope Academic House, September, 10 - November, 30, 2020, Sheffield, UK pp 164-168

Natsvaladze 2020e - Natsvaladze M. Capuchin Monks and the Russian Agents in Georgia in the 80s of the 18th Century, Bridge to science: research works. San Francisco, California, USA September 10-december 152020 http://www.bmpublgroup.com/assets/research-article 127 61.pdf

Natsvaladze 2021a - Natsvaladze M. Unknown backstages of Georgian Diplomacy in the 80-ies of the XVIII Century, European Journal of Humanities and Educational Advancements (EJHEA) Vol. 2 No. 1 (2021), pp 84-91

Natsvaladze 2021b - Natsvaladze M. Russian Empire and Georgian-Austrian Diplomatic Relations in the 80s of the XVIII century. «Humanities and Social Sciences in Europe: Achievements and Perspectives». Proceedings of the 7th International symposium (January 25, 2020). Premier Publishing s.r.o. Vienna. 2021. pp 12-26

Ragsdale 1988 - Ragsdale H. Evaluating the traditions of Russian agression: Catherine II and the Greek Project, Slavonic and East Europeen Review. L., 1988. Vol. 66. N 1; pp. 91-117

Грамоты 1898 - Грамоты и другие исторические документы XVIII столетия, относящиеся к Грузии.Под ред. А. А. Цагарели. Т. ІІ. Вып. 1: Грузинские тексты с 1768 по 1801 год. СанктПетербург 1898209 с

Гриффитс 2013 - Гриффитс Дэвид М. Был ли у Екатерины II «греческий проект»? Екатерина II и ее мир: статьи разных лет. пер. с англ. Е. Леменевой и А. Митрофанова. М.: Новое литературное обозрение, 2013. С. 349-368.

Зорин 2001 - Зорин А. Кормя двуглавного орла. Русская литература и государ-ственная идеология в последней трети XVIII первой трети XIX века. М.: Новое литературное обозрение, 2001. 416 с

Ивонин 2007 - Ивонин Ю.Е. Венцель Антон Кауниц. Вопросы истории. 2007. № 4. С. 27-50.

Маркова 1986 - Маркова О. П. О происхождении так называемого греческого проекта (80-е годы XVIII в.)ю Проблемы методологии и источниковедения внешней политики России.. М., 1986. C. 5-46.

РИО 1872 - Письма императрицы Екатерины II великому князю Павлу Петровичу и великой княгине Марии Федоровне во время путешествия их императорских высочеств в 1781 и 1782 гг. Сб. РИО. СПб., 1872. Т. 9. С. 64-117.

Русский архив 1880 - Переписка Екатерины Великой с Германским Императором Иосифом II-м 1774-1790 Русский архив. Кн. 1. М., 1880. 210-335 с

Русская старина 1892- Собственноручная записка императрицы Екатерины о греческом проекте, Русская старина. 1892. Т. 76. № 10. С. 1-4.

Хаванова 2016 - Хаванова О. В. Пребывание Павла Петровича в Вене в 1781-1782 гг.: «умное» путешествие просвещенного цесаревича, in: Романовы в дороге: путешествия и поездки царской семьи по России и за границу. М.; СПб., 2016. С. 94-109 97

Юзефович 1869 - Юзефович Т. Договоры России с Востоком. СПб., 1869326 с 


\title{
Georgian-Austrian Unknown Preludes \\ of the Treaty of Georgievsk
}

\author{
Natsvaladze Mamuka \\ Sokhumi State University
}

\begin{abstract}
Studying the external policy of the king Erekle II is a topical issue for the modern historiography. The information maintained in the archives of various European cities, namely of Vienna, Vatican and Venice, convey to us the fact that while exercising pragmatic attitude toward relations with the European countries the King of Kartli and Kakheti considered the interests of both his own country and of those European countries as well.

Over the years 1781-82 Erekle II sends his ambassadors to Europe twice: first he sends a Capuchin monk Domenique who dies in Constantinople in uncertain circumstances not having reached the destination; after him Erekle II sends another Capuchin Mauro the Veronese who also dies for unknown reasons while still on his way. It is a very important fact that the letters sent by the King Erekle, unlike the ambassadors, reach their destination which is the Emperor's Court in Austria.

The present article shows the international political background that the king Erekle II had at that time and that he attempted to use for the interests of his country.

The plan of dividing Europe anew, officially developed by the relevant imperial authorities of Saint Petersburg and Vienna, aimed at neutralizing the Ottoman Empire and dividing its territories. According to the Greek Project, it was supposed to resurrect the Byzantine Empire that would be formally independent from Russia but factually acting as a marionette with the Romanov dynasty ruling in it and build Dacia Kingdom as a buffer between the Ottoman and the Austrian Empires.

This project was topical for Erekle II who was trying to get involved in the international political processes to the maximum level as the king of a sovereign and independent country, as in the result of implementation of the Greek Project Georgia would obtain an environment of Christian countries instead of the previous encirclement by Muslim countries. Thus, Georgia would find herself in an absolutely different qualitative dimension that had been a sacred dream of the Georgian Kings at all times.

This was why the Greek Plan held such a great importance for Erekle II. This international project was made secret by the empress Catherine the Great and Joseph II, therefore, the official pragmatic reason that Erekle II referred to when sending ambassadors to Austria which was obtaining financial support for two regiments was merely a mask behind which in reality the ambassadorial mission served the purpose of active involvement and participation in the implementation of the Greek Project.

The Austrian Emperor's Court, on its part, was going to use this intension of the Georgian king for its own pragmatic goals which implied strengthening of the Holy Roman Empire that had been actually made fictitious by that time. The widely acknowledged and reputed international level diplomats of the Austrian Empire Kaunitz and Kobenzl were involved in the process.
\end{abstract}

Key words: the Greek Project; Erekle the Second; Joseph the Second; the Kingdom of Kartli and Kakheti; the Holy Roman Empire; the Empire of Austria, the Russian Empire; Catherine the Second. 